\title{
Journal of Vascenlan' Beseared
}

\section{Abstracts}
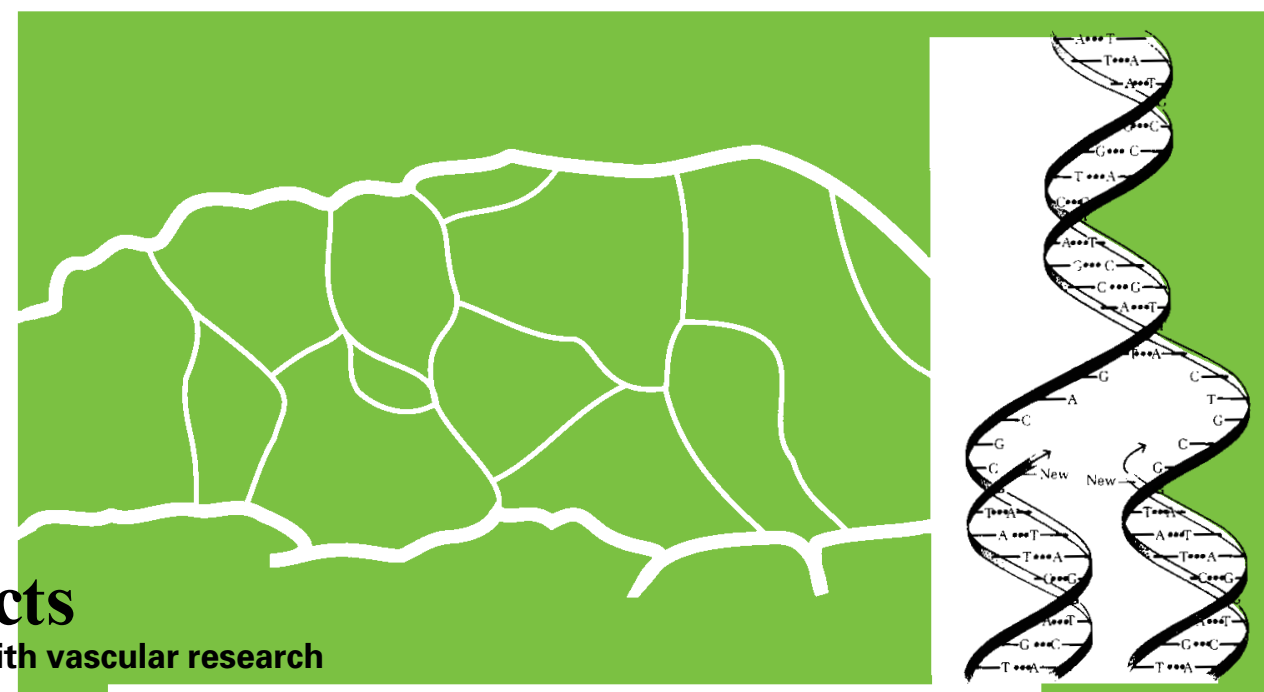

Guest Editor:

R.M.K.W. Lee

Author index at back

INABIS ‘98

5th Internet World Congress on Biomedical Sciences

McMaster University, Canada

December 7-16, 1998

S. Karger

Medical and Scientific

Publishers

Basel $\cdot$ Freiburg

Paris $\cdot$ London

New York $•$ New Delhi

Bangkok $\cdot$ Singapore

Tokyo $•$ Sydney
The preparation of this supplement was supported by an educational grant from Merck Frosst of Canada. 
Endothelial cells (EC) appear to sense mechanical forces partly via structures located at their abluminal surface which may involve signalling via cell-matrix connections. We therefore studied the influence of different matrix proteins on shear stress induced eNOS expression. Primary porcine aortic EC were seeded onto non coated glass plates (NC-EC) or on those precoated with fibronectin (FNEC), laminin I (LN-EC) or collagen (CL-EC). A 6 hours' shear stress of $16 \mathrm{dyn} / \mathrm{cm}^{2}$ was applied. After reaching confluency, only LNEC showed detectable amounts of laminin I in their underlying matrix and responded with a significant, 2-fold increase of eNOS mRNA to shear stress. Likewise, increased eNOS protein and enhanced NO synthesis were found in these cells. Preincubation with YIGSR, a peptide that inhibits EC binding to laminin by a $67 \mathrm{KDa}$ binding protein (LBP) abolished the increase of eNOS expression, whereas a control peptide did not. In contrast, FN-EC and NC-EC did not respond while CL-EC showed only a weak response. It is concluded that a laminin-cell interaction via the $67 \mathrm{kDa}$ LBP is pivotal in the induction of eNOS expression by shear stress. The results further suggest that the matrix composition may decisively modulate shear stress effects on vascular gene expression.

2

CONTRACTILE MECHANISMS AND PEROXIDE SENSITIVITY OF ENDOTHELIN RECEPTOR SUBTYPES

AB Elmoselhi, S.E. Samson, A.K. Grover

Department of Medicine, McMaster University, Hamilton, Ontario, Canada.

Endothelins (ETs) bind to two types of receptor: ETA and ETB. We examined the ET receptor types in the pig coronary artery smooth muscle, contractions they produced, their $\mathrm{Ca} 2+-$ pool utilization and peroxide sensitivity. In Ca2+-containing solution, ET-1 (a nonselective agonist) and IRL1620 (selective ETB agonist) contracted the de-endothelialized rings but the contractions with IRL1620 were much smaller. In Ca2+-free solution, ET-1 contractions were decreased much greater than IRL1620. Treating the rings with peroxide inhibited the contractions produced by both the agents with the following IC50 values in mM: ET-1 in Ca2+ 1.2, ET-1 in Ca2+-free 1.4, IRL1620 in Ca2+ 0.24, and IRL1620 in Ca2+-free 0.14. Pretreating microsomes with peroxide did not affect the binding to either receptor types. Cells cultured from this smooth muscle expressed only ETA receptors and ET-1 produced an increase in cytosolic Ca2+. Treating these cells with $0.3 \mathrm{mM}$ peroxide inhibited $>95 \%$ of this increased. We conclude that: ETB contractions depend more in intracellular $\mathrm{Ca} 2+-$ stores than ETA, ETB is more susceptible to peroxide, and ETA mediated Ca2+-mobilization is more susceptible to peroxide than contraction suggesting that ETA contraction has a $\mathrm{Ca} 2+-$ independent mechanism(s) which is resistant to peroxide. Supported by HSFO.

3

VASCULARISATION OF ISCHAEMIC LIMBS IN SEVERE OCCLUSIVE ARTERIAL DISEASES, A NEW CONCEPT AND AN EASY TECHNIQUE

B.M.S. Kelkar

Hospital for Orthopedic and Reconstructive Surgery, Nasik, India

As separate procedures, fracture near the epiphysis and periosteal elevation performed in a long bone for bone lengthening procedures, have been shown to increase vascularity by formation of an inflammatory vascular leash. Based on these principles, in this series, the corticotomy and periosteal elevation has been used adjacent to the major neurovascular bundles in thirty-six cases of severe occlusive arterial disease [ 22 TAO, 5 Atheroslerosis, 3 Diabetic, 6 Raynaud's disease]. The corticotomy was placed near major neurovascular bundles and the periosteal elevation was performed along the whole length of the adjacent bone. All patients had severe rest pain and would have undergone an amputation in the normal course of the disease. The patients benefited through complete relief of rest pain and an avoidance of amputation in thirty-one out of thirty-six cases. Longest follow up is six years and shortest is six months. Digital Subtraction Angiography studies before and after operation convincingly showed the persistence of a new vascular network. This technique may provide an interesting and useful alternative to treat limbs with extensive vascular disease. 


\section{Ballerini}

Department of Electronic Engineering, University of Florence, Italy

In this work a computational approach for detecting and quantifying diabetic retinopathy is proposed. Particular attention has been paid to the study of Foveal Avascular Zone (FAZ). In fact, retinal capillary occlusion produces a FAZ enlargement. Moreover, the FAZ is characterized by qualitative changes showing an irregular contour with notchings and indentations. Our study is mainly focused on the analysis of the FAZ and on the extraction of a proper set of features to quantify FAZ alterations in diabetic patients. We tried to extract features which can capture not only the size of the object, but also its shape and spatial orientation. The theory of moments provides an interesting and useful way for representing the shape of objects. We used a set of region and boundary moments to obtain a FAZ description which is complete enough for diagnostic purposes and in order to assess the effectiveness of moment descriptors we performed several classification experiments to discriminate diabetic from non-diabetic subjects. The theory of moments provided us with an interesting and useful tool for representing the shape characteristics. In this way we were able to transform the qualitative description of the FAZ used by ophthalmologists into quantitative measurements.

5 ENDOPLASMIC RETICULUM CALCIUM PUMP ISOFORMS EXPRESSED IN ENDOTHELIUM AND SMOOTH MUSCLE OF ARTERIES AND VEINS

I. Khan*, S. Vicky, M.M. Christine, A.K. Grover

*Department of Biochemistry, Faculty of Medicine, Kuwait University, Kuwait and Department of Medicine, McMaster University, Hamilton, Ont, Canada

Endoplasmic reticulum (ER) Ca2+ plays a key role in signal transduction in blood vessels. Here, we compare the expression of mRNA for the ER Ca2+ pump genes SERCA2 and SERCA3 in endothelium and smooth muscle dissected from fresh coronary artery, coronary vein, aorta and vena cava of pig. We first cloned and sequenced a small fragment of SRERCA3 cDNA from pig coronary artery endothelium. This segment had 97, 92 and 90\% identity with SERCA3 from rat, mouse and human, respectively. We then devised an RTPCR protocol to determine SERCA2 and SERCA3 expression. Endothelium from coronary artery, coronary vein and aorta expressed both SERCA2 and SRCA3 mRNA but the endothelium from vena cava expressed only SERCA2. Cells cultured from endothelium of coronary artery also expressed both SERCA2 and SERCA3. Freshly isolated smooth muscle from all the arteries and veins and smooth muscle cells cultured from coronary artery all expressed only SERCA2. We present several hypotheses for the significance of differences in the SERCA3 expression of different vascular beds.

\section{6}

COLOUR SEGMENTATION. ITS EMPLOYMENT IN THE STUDY OF THE ANGIOGENESIS. PART I

R. Rodriguez Morales, T. Alarcon Martinez, I. Castellanos Bisset, R. Wong Navarro*, L. Sanchez Cuello

Group of Digital Signal Processing (GUPDIS), ICIMAF and *Department of Pathology, Hospital "Dr. Carlos J. Finlay"

The obtained results, in colour image, using different segmentation methods with the objective to isolate and to identify blood vessels in histological sections of malign tumours of soft parts are presented. For comparison purpose was realized experiments in divers colour spaces, and it was concluded, that for this type of application and according to the original image, the RGB space is the one which offers better results. It was realized a study of the image for the red, green and blue channel, and is proposed a strategy of segmentation where the experimental results demonstrate that the same is rapid and robust, all this in the environment of a personal computer. In the work was evidenced that red channel is the more noisy and that the green channel is the one which offers greater quantity of information. 

GLAUCOMA

M. Cellini, M. Moretti, P. Versura, A. Rossi, A. Torreggiani

Dept. of Ophthalmology, University of Bologna, Italy

Purpose : To assess the effects of Carteolol, a beta-blocker with ISA, on intraocular pressure, visual field and orbital blood circulation in eyes with chronic open angle glaucoma (COAG). Methods : We studied 30 patients (20 males and 10 females) aged 53 to 68 yrs. (mean 63.4 yrs) affected by COAG. Patients were assigned to a treatment group in a random, double masked fashion. Patients in group A were treated with Timolol $0.5 \%$ and in group B with Carteolol $2 \%$ in both eyes, twice daily. Patients examinations included pneumotonometry, authomatic perimetry and Color Doppler Imaging (CDI) by an Asynchronous-Hitachi analyzer with a $7.5 \mathrm{MHz}$ linear probe in the ophthalmic artery and posterior ciliary arteries, before and after 18 months of therapy. Results : After 18 months of therapy, a reduction of resistance index was observed in patients treated with carteolol, in the posterior ciliary arteries $(\mathrm{p}<0.001)$ with an improvement of $\mathrm{MD}$ ( $\mathrm{p}$ $<0.002$ ) and CPSD ( $\mathrm{p}<0.002$ ) indexes of the automatic perimetry. Conclusions : Carteolol $2 \%$ decreases the intraocular pressure to a lower extent than timolol $0.5 \%$, but its effects on the visual field and CDI indexes are better than timolol $0.5 \%$.

8

THE PREVALENCE AND LINKAGE DISEQUILIBRIUM OF THREE METHYLENETETRAHYDROFOLATE REDUCTASE (MTHFR) GENE POLYMORPHISMS VARIES IN DIFFERENT ETHNIC GROUPS

L.J. Langman, B.Y.-L. Wong*, C. Boggis, L.A. Rubin, D.E.C. Cole. University of Toronto, Toronto, Canada and *The Toronto Hospital, Toronto, Canada.

Homocysteine is recognized as an independent predictor of arteriosclerotic disease, including stroke, myocardial infarction, and peripheral vascular disease. The C677T polymorphism of the MTHFR gene is one genetic factor contributing substantially to the variation in total plasma homocysteine (tHcy). Two other MTHFR polymorphisms -- A1298C and T1317C -- have been identified more recently, but information about the combined prevalence of the 3 sites is still scanty. DNA was isolated from healthy adult populations of Caucasian Canadians $(n=197)$, Asian Canadians $(n=51)$ and African-Americans $(n=51)$. C677T was genotyped by HinfI cleavage of a 198bp PCR product beginning at bp644 and ending in an intronic sequence. A1298C was genotyped by mutation selective PCR (MS-PCR) and the PCR products were digested with BbsI for detection of the $\mathrm{T} 1317 \mathrm{C}$ polymorphism. We found a lower frequency of the 677T polymorphism in African-Americans (13\%, p<0.001) and Asians (30\%, p=0.01), as compared to Caucasians (34\%). For the A1298C polymorphism, there was no difference in $1298 \mathrm{C}$ frequency between Asians (20\%) and Caucasians (30\%), but the allele frequency in African-Americans $(16 \%)$ was significantly lower $(\mathrm{p}=0.01)$ compared to Caucasians . Interestingly, the silent $1317 \mathrm{C}$ polymorphism was seen only once (out of 494 chromosomes) in Caucasians and Asians, but was frequent in African-Americans (37\%). For the 677/1298 haplotype, linkage disequilibrium between sites was substantial in Caucasians (p<0.001). Both 677T and 1298C polymorphisms cause amino acid substitutions in the MTHFR protein and may be independently associated with a significantly elevated tHcy phenotype. However, the variation in linkage disequilibrium we observe may be a significant confounding factor in interpretation of a single genotype. In particular, the assumption that genotyping either C677T or A1298C locus alone is sufficient to identify predisposition to hyperhomocystinemia may be violated to differing degrees, depending on the linkage disequilibrium in the population studied, and the degree to which tHcy is modified by other factors, such as folate status. Further studies of this complex interaction are warranted, if the full effect of MTHFR genotype on tHcy and associated risk for arteriosclerotic disease is to be understood. 

RESTRICTIVE LEFT VENTRICULAR FILLING

N.P. Nikitin, A.L. Alyavi, V.Y. Goloskokova

Department of Internal Medicine, the 1st Tashkent State Medical Institute, Uzbekistan

BACKGROUND: Restrictive left ventricular (LV) filling is associated with more severe chronic heart failure (CHF) and is predictive of cardiac death. This study was designed to determine whether additional vasodilator (nitrate) therapy affects the restrictive filling pattern in patients with CHF. Effects on clinical status, exercise capacity and LV systolic function were also studied. METHODS: We studied 47 patients with $\mathrm{CHF}$ caused by ischaemic heart disease or idiopathic dilated cardiomyopathy (NYHA class II-IV). 23 patients were randomized to standard treatment (digitalis, diuretics and angiotensin-converting enzyme inhibitors) and 24 to a nitrate (isosorbide-5mononitrate $20 \mathrm{mg}$ b.i.d.) in addition to standard therapy. Doppler echocardiography was performed at baseline and after 6 months of therapy. RESULTS: At baseline all patients $(100 \%)$ had a restrictive LV filling pattern (peak early [E] to atrial [A] filling velocity ratio >2 or E/A between 1 and 2 and E wave deceleration time <140 ms). Restrictive LV filling persisted in 61\% ( $\mathrm{n}=14$ ) of patients on standard therapy versus $33 \%(n=8)$ on additional nitrate therapy $(\mathrm{p}<0.05)$. Vasodilator therapy was also associated with a more significant improvement in NYHA class, 6-minute walk distance, left atrial size and mitral regurgitation grade, but not in LV volumes and ejection fraction. CONCLUSIONS: In patients with CHF on standard pharmacological treatment, additional nitrate therapy is effective in reverting a restrictive pattern of LV diastolic filling into a nonrestrictive pattern. This effect is accompanied by an improvement in clinical status and exercise capacity but not in LV systolic function.

10

ANTIOXIDANT N-ACETYLCYSTEINE INHIBITS DEVELOPMENT OF HYPOXIC PULMONARY HYPERTENSION IN RATS

J. Herget, J. Bíbová, V. Hampl

Department of Physiology, 2nd Med. School, Charles University, Prague, Czech Rep.

Chronic hypoxia results in pulmonary hypertension. Radical injury to pulmonary vascular tissue may play pathogenic role (1, 2). We investigated the effect of preventive administration of $\mathrm{N}$-acetyl cysteine (NAC, the precursor of reduced glutathione) in rats exposed to chronic hypoxia. Four groups were studied: $\mathrm{H}=$ exposed to hypoxia $(\mathrm{Fi02}=0.01,2 \mathrm{wks})$ with no additional treatment $(\mathrm{n}=7)$, $\mathrm{H}+\mathrm{NAC}=$ exposed to hypoxia and treated with $2 \mathrm{~g} \%$ of NAC in drinking water $(n=9$. N $(n=7)$ and $N+N A C(n=10)$ were respective normoxic controls. Group H+NAC had significantly $(\mathrm{p}<0.001)$ lower pulmonary arterial blood pressure than group $\mathrm{H}(21+/-1$ torr and $27+/-1$ torr respectively). It was, however, higher than in both groups of air controls $(\mathrm{N}=15+/-1$ and $\mathrm{N}+\mathrm{NAC}=14+/-1$ torr). Similar differences were found in relative weights right ventricle $(\mathrm{H}=73+/-5, \mathrm{H}+\mathrm{NAC}=60+/-4, \mathrm{~N}=46+/-6$ and $\mathrm{N}+\mathrm{NAC}=55+/-2 \mathrm{mg} / 100 \mathrm{~g}$ of body weight). Cardiac output measured by Transonic System (T 106) in open chest, ventilated rats and systemic blood pressure did not differ between the groups. 1. Hoshikawa, Y., S. et al.. Nippon Kyobu shokkan Gakki Yas 33: 1169-1173, 1995. 2. Nakanishi, I., F. et al.. J. Physiol. 489: 869-876, 1995. 
11

EFFECT OF DIETARY SALT ON MYOGENIC RESPONSIVENESS OF PROXIMAL ARTERIOLES AND LOCAL NITRIC OXIDE IN NORMOTENSIVE AND HYPERTENSIVE RATS

T.R. Nurkiewicz, M.A. Boegehold

Department of Physiology, West Virginia University School of Medicine, USA

The aims of this study were to determine if hypertension and/or high salt intake can alter the myogenic behaviour of proximal arterioles in striated muscle, and to assess the modulation of this behaviour by endogenous nitric oxide (NO). Wistar-Kyoto (WKY) and spontaneously hypertensive rats (SHR) fed low-salt $(0.45 \%$, LS) or high-salt $(7 \%$, HS) diets were enclosed in a ventilated airtight box with the spinotrapezius muscle exteriorized for intravital microscopy. Mean arterial pressure was resistant to dietary salt in WKY (LS: $96 \pm 6$ mm $\mathrm{Hg}$, HS: $98 \pm 11 \mathrm{~mm} \mathrm{Hg}$ ), whereas it was significantly higher and augmented by dietary salt in SHR (LS: $163 \pm 4 \mathrm{~mm} \mathrm{Hg}$, HS: $205 \pm 3 \mathrm{~mm}$ $\mathrm{Hg}$ ). Resting arteriolar diameters (D, $40 \pm 3$ to $47 \pm 4 \mathrm{~mm}$ ), wall shear rates (WSR, $579 \pm 44$ to $728 \pm 132 \mathrm{~s}-1$ ) and volume flows (Q, $4 \pm 1$ to $7 \pm 1 \mathrm{nl} / \mathrm{s}$ ) were not different among groups. In all groups, box pressurization to $30 \mathrm{~mm} \mathrm{Hg}$ caused the same increase in arteriolar transmural pressures (servo-null method), resulting in immediate arteriolar constriction. These myogenic responses were similar in WKY and SHR (constrictions of $19 \pm 2 \%$ in WKY-LS vs $17 \pm 5 \%$ in SHR-LS). High salt intake reduced myogenic responses in WKY (7 $\pm 5 \%$ constriction) but not in SHR $(27 \pm 5 \%$ constriction). Constriction magnitude did not correlate with resting WSR or Q in any group, and constriction was sustained despite secondary increases in WSR and decreases in Q. Inhibition of NO synthesis (NG-monomethyl-L-arginine) augmented myogenic responses to a similar extent in WKY-LS $(36 \pm 3 \%)$ and SHR-LS $(35 \pm 6 \%$.), but had no effect in WKY-HS or SHR-HS. Therefore, high dietary salt may alter local blood flow control by suppressing (1) the myogenic activity of proximal arterioles in normotensive rats, and (2) the influence of NO on this activity in normotensive and hypertensive rats. (Supported by NIH HL-44012 and HL-52019

\section{2}

\section{TYROSINE KINASE IN CEREBRAL VASOSPASM}

S. Iwabuchi, J. Zhang, K. Aoki, L.S. Marton, H. Kimura,

H. Samejima

Toho University School of Medicine, Japan, University of Mississippi Medical Center, USA, and University of Chicago, USA

We investigated the involvement of protein tyrosine kinase activity in haemolysate-mediated signal transduction in cerebral smooth muscle cells. Erythrocyte lysate induced, dose-dependently, $\mathrm{Ca} 2+$ release from intracellular stores and Ca2+ entry in rat basilar smooth muscle cells. Preincubation of cells with tyrosine kinase inhibitors genistein, tyrphostin 51, but not tyrphostin A1, an inactive analogue of tyrphostin, reduced remarkably the $[\mathrm{Ca} 2+]$ i response, both $\mathrm{Ca} 2+$ release and $\mathrm{Ca} 2+$ entry, to erythrocyte lysate. Erythrocyte lysate was then fractionated into two parts, molecules smaller or larger 10kDa. Small molecules induced a similar [Ca2+]i elevation to that of unfractionated erythrocyte lysate and large molecules produced only a weak response. Tyrosine kinase inhibitors attenuated the [Ca2+]i response to both fractions. In western blotting, erythrocyte lysate induced an increase in the level of tyrosine phosphorylation of two proteins, approximately 70 and $110 \mathrm{kDa}$, in the cultured rat basilar and rat thoracic aorta smooth muscle cells. We concluded that protein tyrosine kinase mediated the effect of erythrocyte lysate on $[\mathrm{Ca} 2+] \mathrm{i}$ and tyrosine phosphorylation may play a role in cerebral vasospasm. 
Aims: Decreased night-time plasma levels of melatonin were recently reported in patients with coronary artery disease (CAD), and it was postulated that melatonin production may be impaired, due to a lack of synthesising enzymes. However, since artefacts possibly influencing the release pattern were not taken into account, this interpretation was strongly criticised. We therefore carefully reinvestigated night-time melatonin production in patients with CAD using an appropriate experimental approach. Furthermore, we examined the effect of b-blockers, a frequently used drug in CAD therapy. Methods and Results: Forty-eight male patients with angiographically documented severe CAD, 24 of them taking b-blockers daily in therapeutic dosages, were included. Eighteen age-matched men, who did not show atherosclerotic changes in coronary angiography, served as controls. For determination of melatonin production, 6-sulfatoxymelatonin (aMT6s) was measured radioimmunologically in the overnight urine. Urinary aMT6s concentration was highly significantly decreased in patients, and b-blocker treatment did not further suppress melatonin production. Conclusions: The data obtained using this investigative approach provide clearcut evidence that melatonin production in patients with CAD is decreased. Whether a decreased melatonin level may be a predisposing factor to $\mathrm{CAD}$, or whether the occurrence of $\mathrm{CAD}$ decreases melatonin synthesis remains to be determined.

14

\section{PHARMACOLOGICAL MECHANISMS OF CARDIOVASCULAR ACTIONS OF DITERPENOIDS OF ANDROGRAPHIS} PANICULATA

B.K.H. Tan, C.Y. Zhang

Department of Pharmacology, Faculty of Medicine, National University of Singapore, Singapore

Two constituent diterpenoid lactones from the tropical shrub, Andrographis paniculata, 14-deoxyandrographolide (DA) and 14-deoxy11,12-didehydroandrographolide (DDA), were used in anaesthetised rats, isolated rat thoracic aortae and atria and endothelial cell culture to examine their effects on cardiovascular-related parameters. DA and DDA were found to decrease significantly the mean arterial pressure and heart rate of anaesthetised normotensive rats. Both DA and DDA caused relaxation of the isolated rat thoracic aortae through activation of the nitric oxide (NO) synthase and guanylyl cyclase pathways, as well as the blockade of Ca2+ influx via voltage- and receptor-operated $\mathrm{Ca} 2+$ channels. DA and DDA also stimulated NO production in endothelial cells. DDA appeared to be more potent than DA in its vasorelaxant and NO stimulant effects. It was further demonstrated that the hypotensive effect of DDA was mediated through the autonomic ganglion and ?-adrenoceptors, as well as ACE inhibition.

\section{5}

SALT-INDUCED CARDIAC HYPERTROPHY AND GENES EXPRESSION IN STROKE-PRONE SPONTANEOUSLY HYPERTENSIVE RATS, EFFECT OF LACIDIPINE, A LONG-ACTING CALCIUM CHANNEL BLOCKER

J. Kyselovic, N. Morel, M. Wibo, T. Godfraind

Laboratoire de Pharmacologie, Universite Catholique de Louvain, Bruxelles, Belgium

We have previously reported that, in stroke-prone spontaneously hypertensive rats (SHRSP), salt-load induces cardiovascular hypertrophy and overexpression of prepro-endothelin-1 (prepro-ET-1) that are prevented by lacidipine, which protects rats from salt-load, related death. The purpose of the present experiments was to further examine salt-dependent expression of genes and the effects of lacidipine. SHRSP (aged 8 weeks) were randomly allocated to salt free $(\mathrm{n}=10)$ or $1 \% \mathrm{NaCl}$ drinking water during 6 weeks with food containing placebo $(\mathrm{n}=10)$ or lacidipine for a daily mean intake of $0.3(\mathrm{n}=10)$ or $1(\mathrm{n}=10) \mathrm{mg} / \mathrm{kg}$. Salt load increased systolic blood pressure (SBP) from $233 \pm 5$ to $254 \pm 6 \mathrm{mmHg}$ and cardiac mass by $17 \%(\mathrm{P}<0.05)$. Concomitantly, salt-load increased in heart the abundance of adult and 'foetal-type' contractile proteins, of type I collagen and of L-type calcium channel gene products, as well as expression of prepro-ET-1 and of TGF-b1 genes examined by Northern blot analysis $(\mathrm{P}<0.05)$. Lacidipine inhibited the salt-related increase of SBP and ventricular mass, and blunted the associated overexpression of 'foetal-type' contractile proteins, L-type calcium channel, type I collagen, prepro-ET-1 and TGF-b1 $(\mathrm{P}<0.05)$. In conclusion, these results show that lacidipine prevented cardiac remodelling secondary to high salt diet in SHRSP. This indicates that such prevention is not solely observed with ACE inhibitors. 
16

DIFFERENTIAL SIGNAL TRANSDUCTION OF PULSATILE AND STATIC STRETCH IN THE VESSEL WALL

S. Lehoux, A. Tedgui

INSERM U141, Hopital Lariboisiere, Paris

The vessel wall is under constant mechanical stress due to blood pressure and to pulsatile blood flow. Steady and cyclic stretch have both been shown to modulate smooth muscle cell morphology and function. Activation of the mitogen-activated protein kinase (MAPK) cascade is likely to account for at least part of the changes in protein synthesis and gene expression observed. Nevertheless, some responses to mechanical stress are likely to be transmitted via extracellular matrix components, which are incomplete in most in vitro studies. We therefore used an organ model of rabbit aorta, cannulated and perfused 24 hours with DMEM+20\% FCS, to verify effects of steady and cyclic stretch on MAPK activity. Applying a steady pressure of $150 \mathrm{mmHg}$ produced an important rise in MAPK activity compared to control vessels kept at $50 \mathrm{mmHg}$. This increase was blocked by herbimycin A, a Src-family tyrosine kinase inhibitor, but not by other tyrosine kinase inhibitors. On the other hand, submitting aortas to a pulsatile $10 \%$ variation in vessel diameter produced a lesser increase in MAPK activity, which was inhibited at least in part by tyrosine kinase inhibitors genisteine and tyrphostin A48 but not by herbimycin A. Furthermore, only a steady stretch of vessel segments led to an increase in phosphorylation of focal adhesion kinase (FAK). It therefore appears that pulsatile and steady stretch of vessels activates MAPK activity via distinct pathways.

17

\section{TYROSINE KINASE-MEDIATED SERINE PHOSPHORYLATION AND ENHANCEMENT OF ADENYLYL CYCLASE} ACTIVITY

C.M. Tan, R.D. Feldman

University of Western Ontario, London Ontario, Canada

Serine/threonine phosphorylation of adenylyl cyclase (AC) has been shown to regulate enzymatic activity; however, the role of tyrosine kinase-mediated phosphorylation is unclear. We have previously demonstrated that insulin enhances adenylyl cyclase activity (ACA). Further, the insulinomimetic vanadate (a tyrosine phosphatase inhibitor) enhances stimulation of ACA. The cellular mechanisms responsible for this enhancement remain unclear. To examine the effect of tyrosine kinase activation on ACA, an epitope-tagged AC isoform VI (AC6) was constructed and transiently transfected in HEK 293 cells (HEK-AC6). Vanadate mediated a dose-dependent enhancement of forskolin-stimulated ACA. The tyrosine kinase inhibitor Tyrphostin B46 attenuated the vanadate-mediated enhancement of forskolin-stimulated ACA whereas the inactive tyrosine kinase inhibitor Tyrphostin A1 had no effect. To determine whether the vanadate-mediated enhancement of ACA was related to phosphorylation of AC, HEK-AC6 were treated with or without vanadate (300 $\mu \mathrm{mol} / \mathrm{L})$ in the presence of [32P] orthophosphate. Following vanadate treatment, [32P]phosphate incorporation into AC6 was significantly enhanced (316 + 56\% of control); Tyrphostin B46 blunted this effect (to $120+16 \%$ of control). Phosphoamino acid analysis demonstrated that vanadate treatment resulted in a selective increase in phosphoserine, but not phospho-tyrosine nor phosphothreonine content. Anti-AC6 immunoprecipitation/anti-phosphotyrosine immunoblotting demonstrated that AC6 was not directly tyrosine phosphorylated. Thus, vanadate enhances ACA in a tyrosine kinase-dependent manner. This effect parallels a selective enhancement in serine phosphorylation of AC. Phosphorylation of AC may represent an important mechanism by which tyrosine kinase receptor systems modify AC-mediated responses.

18

MIDDLE CEREBRAL ARTERY OCCLUSION IS EFFECTIVE IN PRODUCING ISCHAEMIA OF THE SUPRAOPTIC AND PARAVENTRICULAR NUCLEI OF THE HYPOTHALAMUS

M.O. Hussein, M.C. Curras-Collazo*

Department of Physiology, Ross University School of Medicine and *Department of Neuroscience, University of California at Riverside Magnocellular neuroendocrine cells (MNCs) of the supraoptic (SON) and paraventricular nuclei of the hypothalamus (PVN) are critical to survival since they are involved in the regulation of body water and cardiovascular function. Previous in vivo glutamate excitotoxicity studies have revealed that these nuclei do not succumb to glutamate, ibotenate or NMDLA exposure. To determine if SON and PVN 
MNCs are also resistant to ischaemia we examined the reliability of two stroke models in preventing blood flow to these regions. Deeply anaesthetised adult male rats were randomly assigned to one of three groups: 1) a four blood vessel occlusion group (4BVO) subjected to electrocauterization of both vertebral arteries and ligation of both common carotid arteries (CCA) for 10-30 min; 2) a middle cerebral artery (MCA) occlusion group subjected to permanent middle cerebral and ipsilateral CCA occlusion and transient contralateral CCA occlusion for $3 \mathrm{hr}$; 3) two control groups which were sham-operated as rats in group \#1 or 2 but not subjected to arterial occlusion. During continued occlusion, rats were transcardially perfused with phosphate-buffered saline (PBS) followed by PBS containing 1.0\% Indian ink. Histological examination of brains using cresyl violet counterstaining revealed that Indian ink failed to penetrate the SON and PVN only after MCA occlusion. In separate experiments rats were allowed to survive for 1-3 days post-surgery, were tested for neurological deficits, perfused with $4 \%$ paraformaldehyde under deep anaesthesia and their brains examined. Our preliminary findings indicate that MCNs of the SON and PVN (but not hippocampal neurons) remain viable in both the 4BV and MCA groups.

19

\section{SELECTIVE INDUCTION OF APOPTOSIS IN THE HEART BUT NOT THE AORTA DURING BETA-ADRENERGIC BLOCKADE IN THE SHR}

D. deBlois, B.-S. Tea, P. Hamet

Research Center, University of Montreal Hospital (CHUM), Montreal, Canada

This study examined the response of both cell growth and apoptosis in the heart and aorta of spontaneously hypertensive rats during betaadrenergic blockade therapy. Rats were treated or not with propranolol $(50 \mathrm{mg} / \mathrm{kg} / \mathrm{day})$ for 2 or 4 weeks starting at $10-11$ week of age. DNA synthesis was measured by [3H]-thymidine incorporation in vivo. Apoptosis was quantified by radiolabelling of 3'-OH ends in the extracted DNA with terminal deoxynucleotidyl transferase, followed by gel electrophoresis and quantification by PhosphoImager of radioactivity in oligonucleeosomal DNA fragments. After 4 weeks of treatment, although propranolol did not decrease systolic blood pressure significantly, the heart rate was lowered by $20 \%$ (vs control: $360+17$ beats per minute). In the aorta, propranolol failed to affect vascular growth and apoptosis. In contrast, in the heart we observed that a 4-week treatment caused a significant 3- to 4-fold in apoptosis (vs control: $0.4+0.1$ arbitrary units/ ug DNA; $\mathrm{P}<0.05$ ) and a regression of hypertrophy as measured by the heart to body weight ratio (by $11 \%$ vs control: $5.2+0.1 \times 10 \mathrm{E}-3$ ). These effects were preceded by a transient reduction in DNA synthesis (by $17 \%$ vs control: $831+31$ cpm/100ug DNA; $\mathrm{P}<0.05)$ at 2 weeks of therapy. Taken together, these results suggest that beta-blockade stimulate apoptosis (1) in an organ-specific manner, i.e. in the heart but not the aorta at 4 weeks of therapy, and (2) independently of blood pressure reduction. Supported by MRCC and FRSQ.

20

LOW FREQUENCY ELECTRICAL FIELD STIMULATION ELICITS RESPONSES IN SEGMENTS OF MOUSE TAIL ARTERY WHICH ARE SLOWER IN ALPHA1B-KNOCKOUT MICE THAN IN CONTROL MICE

C.J. Daly, S. Cotecchia*, J.C. McGrath

Neuroscience \& Biomedical Systems, University of Glasgow, Scotland and *Insitut de Pharmacologie et Toxicologie, Universite de Lausanne, Switzerland.

An alpha1b-knockout (KO) mouse has recently been shown to have markedly reduced pressor responses to phenylephrine and reduced adrenergic receptor (AR) number in the liver, heart and brain. We have now examined the potency of exogenously applied and neuronally released noradrenaline (NA) on segments of isolated tail artery of wild type (WT) and KO mice. In WT mice the CRC to NA was shifted to the right by the high affinity alpha1-AR antagonist YM12617 (pKB 9.41) but not by the high affinity alpha2-AR antagonist delequamine (pKB 6.02). The EC50 values for NA in WT (6.93) and KO (6.64) were not significantly different. CEC caused a $20 \%$ depression in the maximum response to NA in both WT (EC50 6.27) and KO (EC50 6.46). Responses to electrical field stimulation (EFS) were transient, returning to baseline within 14 seconds. Responses to low frequency stimulation were significantly smaller in $\mathrm{KO}(4-16 \mathrm{~Hz}$, $\mathrm{p}<0.1)$. Time to EFS induced maximum response ranged from $2.5-2.8 \mathrm{sec}$. WT and $2.9-3.6 \mathrm{sec}$ in $\mathrm{KO}$ ( $\mathrm{p}<0.1 \mathrm{for} 4 \& 8 \mathrm{~Hz})$. A $4 \mathrm{~Hz}(10 \mathrm{sec}$ train) reached maximum amplitude at 6.9 seconds and 9.15 seconds for WT and KO respectively (p<0.1). The slope of the KO response $(\mathrm{mv} / \mathrm{sec})$ was reduced at low frequencies $(4-16 \mathrm{~Hz} ; \mathrm{p}<0.1)$. CEC inhibited the responses to EFS in both WT and KO arteries. These results suggest that the alpha1b-AR may play a role in sympathetic neurotransmission. 
21

DETECTION, SUPPRESSION AND REDUCTION OF MOTION ARTEFACT IN ARTERIAL NEAR INFRARED PLETHYSMOGRAPHY

P.R. Smith, M.J. Hayes

Optical Engineering Group, Loughborough University, UK

Motion artefact corruption of near infrared plethysmography, causing both measurement inaccuracies and false alarm conditions, is a primary restriction in the current clinical practice and future applications of this useful technique. A number of different conceptual approaches to dealing with artefact are discussed and illustrated by example. An inter-comparison between artefact recognition and artefact reduction is made, by employing a spectral analysis method. Limitations of the recognition approach and the reduction method are described. The recognition of severe artefact and the reduction of mild artefact are shown to be essential features of future generalised systems. Recommendations are made for the future design of near infra red systems for arterial vascular measurement and limitations on the interpretation of data from ambulatory or other motion inducing modalities are outlined.

22

DETERMINATION OF A RELIABLE NORMALISATION PROCEDURE FOR THE STUDY OF ISOLATED RESISTANCE ARTERIES ON THE PRESSURE MYOGRAPH

P. Coats, C. Hillier

Vascular Assessment Group, Glasgow Caledonian University, Glasgow, UK.

The effects of longitudinal stretch on vasoreactivity were assessed in isolated, pressurised arteries from the rat mesentery, rat mid-cerebral and human subcutaneous vascular beds. A stretch-dependent increase in reactivity was observed in rat third order mesenteric arteries. In these vessels, maximal agonist-induced vasoconstrictor responses to noradrenaline and phenylephrine were obtained with a longitudinal stretch $(20 \%(0.23(0.04 \mathrm{mN})$. Longitudinal stretch did not affect the response to depolarisation by $30 \mathrm{mM}$ potassium in these arteries. Endothelium-independent and endothelium-dependent mechanisms of vasorelaxation were also unaffected by stretch in rat third order mesenteric arteries. In rat mid-cerebral and human subcutaneous resistance arteries longitudinal stretch did not affect either agonistinduced vasoconstriction or the response to potassium depolarisation. Vasorelaxation responses were not affected by stretch. This study demonstrates that longitudinal stretch in isobaric mounted rat third order mesenteric arteries is an important methodological consideration. These results suggest that isobaric mounted rat third order mesenteric arteries are stretched (20\% to provide optimal experimental conditions for pharmacological studies.

23

\section{THE PORTAPRES IN THE NON-INVASIVE ASSESSMENT OF DYNAMIC CARDIOVASCULAR FUNCTION}

N.L. Mills, J. Spratt, P.L. Padfield, D.J. Webb

University of Edinburgh, UK.

Background: Non-invasive methods of assessing haemodynamics have an increasing role to play in the understanding of cardiovascular physiology. We investigated the PORTAPRES, a portable method of measuring beat-to-beat blood pressure and cardiovascular haemodynamics and compared it with the established method of impedance cardiography (BoMED). Methods: Mean arterial pressure (MAP), heart rate (HR) and cardiac index (CI) and systemic vascular resistance were measured in 8 healthy male subjects using the PORTAPRES and BoMED at identical time points at rest and following each stage of a seven stage graded exercise schedule. Differences between paired readings using the techniques were compared by Bland \& Altman analysis. Results: Although strong correlations were seen between techniques with MAP $(r=0.74)$ and percentage change in CI $(r=0.79)$, absolute measurements of MAP and CI were lower with PORTAPRES. Reproducibility at rest was excellent (within subject coefficients of variation $6.3-8.5 \%$ ). On exercise, the percentage change from baseline was comparable for MAP $6.1 * 17 \%$ (mean difference * SD) and CI $6.1 * 29 \%$. Conclusion: In our study relative rather than absolute changes were best represented. Although differences in MAP represented differences in measurement site, the PORTAPRES measured CI consistently low. We conclude that the PORTAPRES is a simple and convenient tool for continuous ambulatory monitoring of MAP and CI, however, absolute values, especially of CI, are too inaccurate for its use in clinical practice. 

VASCULAR REACTIVITY IN VIVO AND IN VITRO

D. Henrion*, J. Benessiano, I. Philip, G. Plantefève, D. Chatel, B.I. Lévy*.

Hop. Bichat, Paris, France and *INSERM U 141, Hop. Lariboisière, Paris, France

The deletion allele (D) of the angiotensin converting enzyme (ACE) might be associated with some cardiovascular diseases. We studied in vivo and in vitro, phenylephrine (PE)-induced tone and the effect of angiotensin II (AII) on PE-induced tone. During bypass surgery PE-induced contraction was studied in patients with acute hypotensive events. Excess material of internal mammary artery was then mounted in an organ chamber, in vitro. In patients under extra-corporeal circulation PE ( $75 \mu \mathrm{g})$ induced higher contractions in patients with the DD genotype $(20.0 \pm 2.8$ vs $11.2 \pm 2.3 \mathrm{mmHg} / \mathrm{ml} / \mathrm{min})$. In the mammary artery, in vitro, contractions to PE or AII were not affected by the genotype. AII $(10 \mathrm{pM})$ significantly potentiated PE $(1 \mu \mathrm{M})$-induced contraction $(17 \pm 5 \%$ increase in tone). This potentiation was higher in DD than in II/ID patients $(0.30 \pm 0.08$ vs $0.15 \pm 0.04 \mathrm{mN} / \mathrm{mg}$ increase in PE-induced tone after AII). Thus, the DD genotype was associated with an increased reactivity to PE in vivo and potentiating effect of exogenous AII in vitro. The higher response to PE in vivo might reflect a higher potentiation by endogenous AII.

\section{5}

\section{THE CHANGE OF OCULAR BLOOD FLOW AFTER TOPICAL INSTILLATION OF UNOPROSTONE EYE DROPS}

K. Emi, Y. Ito, A. Nishi, Y. Uji

Emi Eye Clinic, Japan, Mie General Medical Center, Japan, and Mie University School of Medicine, Japan

Purpose: To assess the change of ocular blood flow after topical application of unoprostone(prostaglandin-related compound) eye drops on the normal subjects. Subjects and Method: Eighteen normal subjects were examined, including fourteen females and four males. The averaged age was 71 years old, ranging from 60 to 84 years old. The LOGIQ500 colour Doppler imaging unit was used to examine all of the subjects. Before and two hours after the application of unoprostone, we tried the colour Doppler imaging and pulse Doppler method to detect the blood flow of the CRA and PCA. Results: Peak-systolic, mean and end-diastolic blood flow velocities were increased after the instillation of unoprostone for both CRA and PCA. $(\mathrm{p}<0.01)$. Pulsatility indices were not changed in either vessel. Conclusion: The unoprostone improves the ocular blood circulation of the orbital vessels.

26

FUNCTIONAL ALTERATIONS IN RAT BASILAR ARTERY INDUCED BY CHRONIC INHIBITION OF NITRIC OXIDE SYNTHASE (NOS). ARE THEY RELATED TO VASCULAR REMODELLING?

S.M. Arribas*, J.C. McGrath, A.F. Dominiczak, M.C. Gonzalez*.

University of Glasgow. Scotland. U.K. and *Universidad Autonoma de Madrid. Spain

Chronic inhibition of NOS induces hypertension and structural alterations in rat basilar arteries: reduced lumen, decreased smooth muscle and endothelial cell number, increased adventitial cell number and thickness (Arribas et al., J.Hypert. 15:1685-1693, 1997). Objective: to determine the functional alterations related to these changes. Methods: WKY rats treated for 3 weeks with $10 \mathrm{mg} / \mathrm{kg} / \mathrm{day} \mathrm{L}-\mathrm{NAME}$, $\mathrm{n}=10$; or untreated, $n=11$ were used. Function was studied with wire myography at 0.91100 . Results: L-NAME treatment reduced bradykinin relaxations (untreated max. $=75.5 \pm 7.5 \%$; L-NAME max. $=21.6 \pm 6.8 \%, \mathrm{p}<0.01$ ) and increased serotonin (untreated max. $=1.5 \pm 0.2 \mathrm{mN} / \mathrm{mm}$; L-NAME max. $=2.8 \pm 0.3 \mathrm{mN} / \mathrm{mm}, \mathrm{p}<0.01$ ), but not $\mathrm{KCl}$ contractions. Pre-incubation with L-arginine had no effect on bradykinin responses, but significantly reduced serotonin contractions. Conclusions: In rat basilar arteries chronic L-NAME treatment reduces endothelium-derived NO production and induces iNOS. The reduction of smooth muscle cell number induced by treatment is not related to an alteration of contractile capacity and can be explained by the iNOS induction in the vessel wall. Supported by MRC, Wellcome Trust and CAM 

Northwestern Univ. Med. Sch., Chicago, IL 60611 USA

Microvascular endothelial cells have the ability to internalize and subsequently to transport albumin via transcytosis, a process that depends on albumin binding and activation of cell surface, $60 \mathrm{kDa}$ albumin-binding glycoprotein, gp60. To study membrane dynamics of endocytosis and transcytosis activated by gp60, we used the interfacial, hydrophilic fluorophore FM 1-43 to mark plasmalemma-derived vesicles in bovine pulmonary microvascular endothelial cells. Incorporation of FM 1-43 into endosomes as measured by quantitative digital fluorescent microscopy increased by cross linking gp60 using an anti-gp60 antibody and a secondary antibody. Within 5 min of gp60 activation by addition of albumin $(6 \mathrm{mg} / \mathrm{ml})$ to endothelial cells, fluorescence from FM 1-43 and a cy3-labeled anti-gp60 antibody was co-localized in identical endosomes at the apical cell surface as determined by confocal imaging. Co-localized fluorescence disappeared from the basolateral surface over $45 \mathrm{~min}$ as the fluid phase marker (FM1-43) was released by exocytosis whereas cy3fluorescence persisted in the basolateral membrane. Fluorescently labeled anti-caveolin-1 and anti-gp60 antibodies were co-localized, indicating that vesicles forming as result of gp60 activation originated from caveoli. Treatment of endothelial cell monolayers with pertussis toxin inhibited both cellular uptake of 125I-labeled bovine serum albumin and FM1-43 incorporation induced by cross linking gp60. Expression in endothelial cells of the Gi carboxy- terminal peptide sequence of 11 amino acids abolished the endocytosis induced by gp60 cross linking. We conclude that (a) gp60 stimulates albumin transcytosis in microvascular endothelial cells, (b) gp60-activated vesicles co-localize with caveolin-1, and (c) mechanism of gp60-activated endocytosis involves signalling via the heterotrimeric guanine nucleotide binding protein, Gi.

\section{8}

\section{SPECIES DIFFERENCE OF ENDOTHELIUM-DEPENDENT VASORELAXATION IN MIDDLE CEREBRAL ARTERIES}

\section{H. Dong, C.R. Triggle}

Smooth Muscle Research Group, Faculty of Medicine, University of Calgary, Canada

The contributions of nitric oxide (NO), prostacyclin (PGI2) and endothelium-derived hyperpolarizing factor (EDHF) to cerebral vasorelaxation appear to depend on different species. However, the mechanisms still remain elusive. The present study was undertaken to compare systematically their contributions to acetylcholine (ACh)- induced relaxation of the middle cerebral arteries isolated from rabbit (RMCA) and guinea-pig (GPMCA). In RMCA, ACh-induced relaxation was sensitive to either indomethacin (Ind, $10 \mu \mathrm{M}$ ) or NG-nitro-Larginine (L-NNA; $100 \mu \mathrm{M}$ ) and abolished by their combination. In the presence of Ind, relaxation to ACh in RMCA was inhibited by charybdotoxin $(\mathrm{CTX} ; 0.1 \mu \mathrm{M})$ and ODQ $(10 \mu \mathrm{M})$. In the presence of L-NNA, relaxation to ACh was reduced by CTX and SQ-22536 (10 $\mu \mathrm{M})$. In contrast, ACh-induced relaxation of GPMCA was not abolished by L-NNA plus Ind. This L-NNA/Ind insensitive relaxation was inhibited by iberiotoxin $(0.1 \mu \mathrm{M})$, completely blocked by external high $\mathrm{K}+\mathrm{PSS}$, CTX or clotrimazole $(1 \mu \mathrm{M})$. These results indicate the contributions of NO, PGI2 and EDHF to endothelium-dependent vaso- relaxation vary in a species- dependent fashion: 1) NO and PGI2 are involved in the relaxation of RMCA, 2) NO and EDHF are involved in the relaxation of GPMCA and EDHF in this vessel may be a cytochrome P450- derived metabolite. 


\section{CARDIOVASCULAR EFFECTS OF CPU-23, A NEW SYNTHETIC DRUG BASED ON CHINESE MEDICINAL DRUGS}

H. Dong

Smooth Muscle Research Group, Faculty of Medicine, University of Calgary, Canada

Tetrandrine, a new calcium channel blocker isolated from the Chinese medical herb, has been used clinically in China to treat angina and hypertension with good results. However, its chemical synthesis is difficult because of complicated structure and it has less potency and selectivity for blood vessels compared with dihydropyridines. In order to simplify the chemical structure of tetrandrine and find better therapeutic agents, we have synthesized and screened, using both $[3 \mathrm{H}]$-nitrendipine binding and biological assays, a series of benzyltetrahydroisoquinolines (half-molecules of tetrandrine). CPU-23, the most potent compound identified in this series, was found to inhibit $\mathrm{KCl}$-induced contraction of rat aorta and displace [3H]-nitrendipine binding in rat cerebral cortical membranes with similar potency. CPU-23 also behaves as a simple competitive inhibitor at the $[3 \mathrm{H}]$-nitrendipine binding sites. Whole-cell patch-clamp experiments revealed that CPU-23 dose-dependently blocked L-type $\mathrm{Ca} 2+$ channels and delayed rectifier $\mathrm{K}+$ channels in single smooth muscle cells isolated from rat tail artery and rabbit portal vein. In addition, it inhibited $\mathrm{KCl}$-induced $\mathrm{Ca} 2+$ influx and action potential characteristics of myocardial preparation in vitro and induced hypotension and bradycardia in rat in vivo. It is indicated that CPU-23 is a novel potent calcium and delayed rectifier $\mathrm{K}+$ channels blocker, which has therapeutic potentials of anti- hypertension and antiarrhythmics.

30

\section{HEMODYNAMIC EFFECTS OF TETRANDRINE IN PORTAL HYPERTENSIVE RATS}

\section{Y.-T. Huang}

Institute of Traditional Medicine, National Yang-Ming University, Taiwan

Background/Aims: Tetrandrine, a bis-benzyltetrahydroisoquinoline alkaloid isolated from the Chinese herb Stephania tetrandra S. Moore, is a vasodilator with L-type calcium channel blocking activities. We investigated its acute and chronic effects in portal hypertensive rats. Methods: Portal hypertension was induced by either partial portal vein ligation (without cirrhosis)or bile duct ligation (with cirrhosis) in Sprague-Dawley rats. Results: Acute intravenous infusion of tetrandrine $(2-24 \mathrm{mg} / \mathrm{kg})$ and chronic administration of tetrandrine (10-50 $\mathrm{mg} / \mathrm{kg}$, bid, by gavage for 9 days)induced dose-dependent reduction of portal venous as well as mean arterial pressure in portal hypertensive rats. Chronic tetrandrine treatment also ameliorated the splanchnic hyperaemic state of portal hypertensive rats. When used in combination with other western portal hypotensive drugs such as propranolol, terlipressin, or octreotide, only the combination of tetrandrine and terlipressin yielded beneficial therapeutic effects in terms of side-effect reduction of terlipressin. No benefits in terms of efficacy enhancement were observed for each combination regimen of tetrandrine with western drugs. Conclusion: Acute and chronic administration of tetrandrine exerted portal hypotensive effects in portal hypertensive rats. In combinations of tetrandrine with other western drugs, only in the case of tetrandrine and terlipressin did benefits of side-effect reduction were observed.

\section{1}

\section{MODULATION OF POTASSIUM CHANNEL CURRENTS BY CARBON MONOXIDE IN DIABETIC SMOOTH MUSCLE CELLS}

R. Wang

Department of Physiology, University of Saskatchewan, Saskatoon, SK, Canada

The altered metabolism of CO in diabetes has been demonstrated. The vasoactive effects of CO in diabetes, however, were unknown and were investigated. The CO-induced vasorelaxation of tail artery tissues from streptozotocin-induced diabetic rats was significantly decreased as compared to that in non-diabetic control rats. Single channel conductance of KCa channels in diabetic tail artery smooth muscle cells (SMCs) was not different from that of normal SMCs, being around $225 \mathrm{pS}$. However, the gating pattern of KCa channels was significantly different between control SMCs and diabetic SMCs. CO $(10 \mu \mathrm{M})$ had no effect on the single channel conductance of KCa channels in diabetic or non-diabetic SMCs. In control SMCs, CO at $10 \mu \mathrm{M}$ induced a $81 \pm 24 \%$ increase in the mean open probability of single KCa channels. In contrast, at the same concentration $\mathrm{CO}$ did not alter the mean open probability of KCa channels in diabetic SMCs. Our results suggest that the decreased vasorelaxant effect of CO in diabetic rats could be related to a reduced sensitivity of KCa channels in the diabetic SMCs to CO. (Supported by research grants from Heart \& Stroke Foundation of Canada, NSERC of Canada, and Saskatchewan Lung Association.) 


\section{CELLS}

L. Wu, R. Wang*

Groupe de recherche sur le système nerveux autonome, Université of Montréal, Canada and * Department of Physiology,

University of Saskatchewan, Canada

Metalloporphyrins, especially zinc protoporphyrin XI (Zn-PP-IX), have been widely used as the specific blocker of heme oxygenase (HO) to reduce the endogenous generation of carbon monoxide (CO). In the present study, it was found that $\mathrm{Zn-PP-IX} \mathrm{induced} \mathrm{a}$ concentration-dependent $(10 \mu \mathrm{M}$ to $300 \mu \mathrm{M})$ transient increase in intracellular free calcium concentrations, [Ca2+]i, in cultured vascular smooth muscle cells (SMCs) from rat tail artery. This effect was not extracellular calcium dependent and was blocked by thapsigargin. The Zn-PP-IX-induced intracellular calcium release was unlikely mediated by HO activities since that (1) bathing the vascular SMCs with the CO-containing Earle's solution did not induce any changes in [Ca2+]i; that (2) Zn-DPBG, but not Sn-PP-IX, induced a similar transient increase in $[\mathrm{Ca} 2+] \mathrm{i}$ in these vascular SMCs; and that (3) light-treated Zn-PP-IX still induced a transient increase in [Ca2+]i in vascular SMCs. It is important that when evaluating the biological functions of endogenous $\mathrm{CO}$, a conclusion should not be readily made solely based on the effect of Zn-PP-IX even at relatively low concentrations. (Supported by Heart \& Stroke Foundation of Canada).

33 CA2+ SIGNALLING IN MACROVASCULAR ENDOTHELIUM: ROLE OF ION CHANNELS

B. Nilius, M. Kamouchi, J. Eggermont, G. Droogmans

KU Leuven, Campus Gasthuisberg, Department of Physiology, B-3000 Leuven, Belgium

$\mathrm{Ca} 2+$-signals in endothelial cells (EC) are determined by release from intracellular stores, entry through the plasma membrane, and a variety of $\mathrm{Ca} 2+$ sequestration mechanisms. The membrane potential sensitively regulates $\mathrm{Ca} 2+$. Nature of $\mathrm{Ca} 2+$ entry and its control by the membrane potential are discussed. At least two different types of Ca2+ - entry channels exist: 1 . A CRAC-like, highly selective Ca2+ channel which a small current density $(0.1 \mathrm{pA} / \mathrm{pF}, 0 \mathrm{mV})$. No molecular candidate has been identified so far in EC although a differential expression of trp1,3,4 has been detected in endothelial cells. 2. A non-selective cation channel (NSC) which is regulated by agonistinduced Ins(1,4,5)P3 production, requires a permissive intracellular Ca2+-concentrations but is only weakly regulated by intracellular $\mathrm{Ca} 2+$ stores. Expression of htrp3 induces functional channels, which resemble NSC. The following ion channels regulate the driving force for $\mathrm{Ca} 2+$ entry: an inwardly rectifying $\mathrm{K}+$ channel (Kir2.1), a big-conductance, a Ca2+-activated $\mathrm{K}+\mathrm{channel}(\mathrm{BKCa}$; identified as hslo encoded channel) and at least two $\mathrm{Cl}$ - channels (a volume regulated anion channel, VRAC, and a Ca2+ activated $\mathrm{Cl}-\mathrm{channel}$, CaCC). Some EC only express the a-subunit of hslo. Coexpression of the B-subunit sensitises BKCa, induces channel-clustering, accentuates agonist-induced hyperpolarization and improves $\mathrm{Ca} 2+$ signalling. Blockers of VRAC are efficient to support Ca2+ entry and may provide a new class of tools interfering with NO release.

\section{4}

SIGNALLING MECHANISMS INVOLVED IN ENDOTHELIAL CELL ACTIVATION BY PERTURBED FLOW

P.I. Lelkes, C.S. Kettlun, J. Wigboldus, C.R. Waters,

D.A. Sukovich*, G.M. Rubanyi*

Univ. Wisc. Med. School, MCC, Milwaukee, WI and

*Cardiovascular Research, Berlex Biosciences, Richmond CA

The focal establishment of atherosclerotic lesions in distinct segments of arterial vessels exposed to perturbed (low shear, non-laminar, pulsatile), blood flow (PF) is preceded by the upregulation of endothelial cell (EC) adhesion molecules, such as Vascular Cell Adhesion Molecule-1 (VCAM-1) in these sites of "atherosclerotic predilection". To test the hypothesis that low-shear PF conditions activate the expression of adhesion molecules on cultured EC's, we exposed human aortic EC in specially designed flow/cell culture chambers to PF (0.01 - 1.5 dynes $/ \mathrm{cm} 2,100 \mathrm{ml} / \mathrm{min})$ and measured the expression of VCAM-1 using a whole cell ELISA. In contrast to the well-studied downregulation of VCAM-1 in EC exposed to laminar shear stress, exposure for 5 hours to PF resulted in a $>7$ fold upregulation of VCAM-1, which was abrogated by antioxidants (PDTC, NAC). PF activated distinct cellular signalling pathways, such as the MAPK cascade (erk-1/2), as well as integrin-mediated signalling (FAK and paxillin). Using electrophoretic mobility shift assays, we failed to 
detect PF-mediated enhanced nuclear translocation of the redox-sensitive transcription factors NF-kappaB and AP-1. This result is surprising, since both these transcription factors are activated by laminar flow. By contrast, exposure to PF resulted in the upregulation of two other transcription factors, SP-1 and EGR-1. These results suggest that exposure of cultured endothelial cells to PF can mimic early manifestations of atherosclerotic lesions, such as the upregulation of VCAM-1.

35

DIFFERENTIAL VASCULAR EFFECTS OF PANAX GINSENG AND PANAX QUINQUEFOLIUS EXTRACTS

C.Y. Kwan

Department of Medicine, McMaster University, Canada

PURPOSE: To study and compare the vascular effects of the commercial sources of extracts prepared from the root of Panax ginseng (G115 ) and the leaf and stem of Panax quinquefolius (PQS). METHODS: Isometric contractile responses were investigated using deendothelialized rings of dog carotid artery (DCA) and rat aorta (RAO). RESULTS: G-115 (0.6 mg/ml) inhibited the myogenic tone in the aorta of spontaneously hypertensive rats (SHR) and had no effect on the basal tension of the aorta of the Wistar/Kyoto normotensive control rats (WKY). G-115 also inhibited the RAO contraction induced by $\mathrm{NaCl}$ or phenylephrine (PE) but not that induced by $\mathrm{KCl}$. However, PQS $(0.5 \mathrm{mg} / \mathrm{ml})$ was found to inhibit KCl-induced contraction in DCA rings much more prominently than that induced by PE. DISCUSSION: The vascular effects of G-115 appeared to be very similar to those obtained with the total saponins extracted from Panax notoginseng (PNS) in that it inhibits PE-induced contraction, but not KCl-induced contraction. We have previously reported that the total ginsenosides isolated from the root of Panax quinquefolius, unlike PNS, G-115 or PQS, enhanced the contractile responses of dog mesenteric artery to suboptimal concentration of PE. CONCLUSION: Differential vascular effects were observed in ginseng extracts obtained from different ginseng products and may be due to the different gensenoside compositions in these products.

\section{6}

REMODELLING OF MESENTERIC RESISTANCE ARTERIES IN THE GENETICALLY HYPERTENSIVE (GH) RAT; EFFECTS OF TREATMENT WITH AN ACE INHIBITOR, AN ANGIOTENSIN II RECEPTOR ANTAGONIST AND A CALCIUM ANTAGONIST

J. Ledingham, R. Laverty

Department of Pharmacology, Otago University Medical School, New Zealand

In the GH rat strain BP is raised from an early age and cardiovascular structure is altered. To observe the effects of different drug classes on vascular structure we treated GH from age 4-10 weeks with enalapril, losartan or felodipine and measured effects on BP, left ventricular (LV) mass and on structural remodelling of mesenteric resistance arteries (MRA). The mesenteric arcade was fixed by perfusion, 2nd order branches of mesenteric arteries were embedded in Technovit and stained sections analysed using stereological methods. Enalapril and losartan significantly lowered BP and LV mass to normal levels. Felodipine treatment lowered BP and LV mass significantly but they were not normalised. In MRA, enalapril and losartan reduced the ratio of media width/lumen diameter to below normal by a large increase in lumen diameter (eutrophic outward remodelling), while felodipine lowered the ratio to normal through significant media reduction as well as increased lumen size (hypotrophic outward remodelling). In felodipine treated GH, structural changes in MRA occurred even when BP was not normalised suggesting that they are not wholly dependent on BP. Since both enalapril and losartan treatment led to the same structural remodelling the structural changes are probably due to blocking of angiotensin rather than any bradykinin effect. 
37

INWARD HYPERTROPHIC REMODELLING IN SUBCUTANEOUS SMALL ARTERIES OF PATIENTS WITH RENOVASCULAR HYPERTENSION, BUT NOT WITH PRIMARY ALDOSTERONISM

D. Rizzoni, E. Porteri, A. Piccoli, M. Castellano, G. Bettoni, G. Pasini, M.J. Mulvany*, R.E. Agabiti

Scienze Mediche University of Brescia, Brescia IT and *University of Aarhus, Aarhus Denmark

Vascular structural alterations in small resistance arteries of patients with essential hypertension are mostly characterized by inward eutrophic remodelling. However, experimental models of hypertension with high circulating renin are characterized by the presence of smooth muscle cell hypertrophy. The aim of our study was to investigate at the cellular level the structural characteristics of subcutaneous small resistance arteries in patients with primary or secondary forms of hypertension, using "the disector". Fifteen patients with renovascular hypertension $(\mathrm{RVH}), 8$ with primary aldosteronism, 13 with essential hypertension and 9 normotensive subjects have been included in the study. A biopsy of subcutaneous fat was taken from all subjects. Small arteries were dissected and mounted on a micromyograph and the media/lumen ratio (M/L) was calculated. The cell volume (CV) and the number of cell per segment length (NC). The M/L and the CV was significantly greater in RVH compared with the other groups. No difference in NC was observed between groups. In conclusion, an inward hypertrophic remodelling, as evaluated by a direct, unbiased method, was observed only in small resistance arteries of RVH. Therefore, for the first time our data demonstrated that a pronounced activation of the renin-angiotensinaldosterone system is associated to vascular smooth muscle cell hypertrophy also in human hypertension.

38

REGULATION OF AT1 ANGIOTENSIN RECEPTOR GENE EXPRESSION IN VASCULAR SMOOTH MUSCLE CELLS

T.J. Murphy

Department of Pharmacology, Emory University School of Medicine, Atlanta, USA

Several classes of agonists down regulate AT1-receptor gene expression in rat vascular smooth muscle cells (VSMC). This is associated with a fairly rapid loss of the AT1-R mRNA. New studies in VSMC provide compelling evidence that regulation of AT1-R mRNA levels is a dominant pathway for specification of cell surface AT1-R protein levels. Agonists of growth factor and Gq-coupled receptors inhibit transcription of the AT1-R gene, but little is understood about how this occurs mechanistically. However, this effect alone cannot fully explain the loss of mRNA stimulated by agonists. Cyclic AMP-elevating agents do not affect VSMC AT1-R gene transcription, and protein kinase A mediated destabilization of the AT1-R mRNA contributes substantially to AT1-R down regulation by some, but not all classes of agonists. Powerful new systems, including a retroviral tetracycline regulated vector, have been created to express recombinant AT1-R minigenes in VSMC. With these, post-transcriptional processes can be experimentally separated from the complications of transcriptional effects by agonists on the native gene. Their use is accelerating our understanding of the mechanisms underlying signallingregulated AT1-R mRNA stability control in VSMC.

\section{9}

\section{ARTERIAL STRUCTURE, ENDOTHELIAL DYSFUNCTION AND EFFECTS OF ANTIHYPERTENSIVE TREATMENT}

E.L. Schiffrin

Clinical Research Institute of Montreal, University of Montreal, Canada

Small arteries may play a role in the development and complications of hypertension. The changes occurring in small arteries may result in part from the action of hormones (such as angiotensin II) and calcium-dependent mechanisms. These changes may include cell growth and apoptosis, and increased extracellular matrix and collagen deposition. Treatment of spontaneously hypertensive rats with angiotensin converting enzyme (ACE) inhibitors, calcium channel antagonists, and angiotensin receptor antagonists has improved the altered structure and endothelium-dependent relaxation of small arteries. In hypertensive patients some ACE inhibitors or extended release calcium channel antagonists induced similar effects in small arteries obtained from gluteal subcutaneous biopsies: both structure and endothelial dysfunction improved. Equally controlled patients receiving the beta blocker atenolol did not exhibit in any of 3 studies any improvement in small artery structure or endothelial function. Thus, hypertensive patients with good blood pressure control treated for more than one year with ACE inhibitors or long acting calcium antagonists exhibit normal structure and function of small arteries, whereas similarly controlled beta blocker-treated patients present abnormally thick small arteries with impaired contractility and endothelium-dependent relaxation. It will be important to determine whether this contributes to a reduced morbidity and mortality in hypertensive patients. 
40

\section{ROLE OF NON-SELECTIVE CATION CHANNELS IN ENDOTHELIAL PHYSIOLOGY AND PATHOPHYSIOLOGY}

K. Groschner, B. Lintschinger, M. Balzer

Department of Pharmacology and Toxicology,Universität Graz, Austria

Endothelial cells respond to a variety of stimuli with activation of cation conductances that allow Na+ entry and membrane depolarization. Physiologic control of endothelial functions, e.g. via IP3-mediated release of Ca2+ from intracellular stores, as well as pathophysiologic dysfunction, e.g. in oxidative stress, are associated with activation of poorly selective cation channels. The molecular nature of these cation channels is still unclear. Recent evidence indicates that homologues of the Drosophila Trp protein may form cation channels in endothelial cells. This hypothesis was tested for human umbilical vein endothelial cells (HUVEC). RT-PCR experiments provided evidence for the expression hTrp1,3 and 4 in HUVEC. The role of Trp proteins in the IP3-induced cation conductance was tested by expression of an N-terminal fragment of hTrp3 (N-TRP) which exerts a dominant negative effect on Trp channel function. Intracellular administration of IP3 $(100 \mu \mathrm{M})$ induced a substantial non-selective cation conductance in sham-transfected HUVEC. In contrast, HUVEC transfected with the dominant negative N-terminal fragment of hTrp3 failed to exhibit any non-selective cation currents upon challenge with IP3. Our results strongly suggest involvement of Trp proteins in non-selective cation conductances of vascular endothelial cells. The role of Trp channels in endothelial physiology and pathophysiology is discussed.

41

SPASMOGENS AND CEREBRAL VASOPASM

J. Zhang*, L.S. Marton, B. Weir, L. Johns, Y.Y. Guan,

M.S. Stoodley, A. Kowalczuk

University of Chicago, Chicago and *University of Mississippi, Jackson, Mississippi, USA

These studies determined the spasmogen(s) responsible for vasospasm. Application of fresh erythrocyte hemolysate to cerebral smooth muscle increases intracellular calcium ([Ca2+]i) that is mediated by adenosine triphosphate (ATP). Pure haemoglobin does not increase $[\mathrm{Ca} 2+]$ i. ATP concentrations declined rapidly in haemolysate from erythrocytes incubated in vitro. A combination of low and high molecular weight components of incubated haemolysates was needed to increase $[\mathrm{Ca} 2+] \mathrm{i}$,. To determine whether small molecules like ATP cause vasospasm, we placed agarose containing autologous haemolysate, ATP or pure haemoglobin into the subarachnoid space of monkeys. There was significant vasospasm after ATP, haemolysate or haemoglobin placement. Haemoglobin and ATP levels were measured in cerebrospinal fluid and clots from the subarachnoid space of humans and monkeys at different times after subarachnoid haemorrhage. Haemoglobin remained at high levels for days but ATP declined within 48 hours to levels that would not contract arteries. To determine when blood clot had to be present and for how long in order to cause vasospasm, monkeys had bilateral SAH and serial angiography. Subarachnoid clot was removed on day 1, 3, 5 or not removed in controls. Vasospasm required subarachnoid clot through day 3. Clot removal on day 1 or 3 reversed spasm 4 days later whereas clot removal on day 5 did not alter vasospasm on day 7 or 9 . While ATP levels were high enough acutely to cause vasospasm, there was no ATP in clot on day 3, yet vasospasm requires this clot. Multiple substances of different molecular weights may cause vasospasm. The substances may be different at different times. 
42

LESSONS FROM RECOMBINANT ENDOTHELIAL NITRIC OXIDE SYNTHASE GENE TRANSFER TO CEREBRAL ARTERIES A.F.Y. Chen, Z.S. Katusic

Departments of Anesthesiology and Pharmacology, Mayo Clinic, USA

Gene therapy involves the transfer of functional genes to host cells in order to correct the malfunction of a specific gene. Gene transfer to cerebral blood vessels is not only a powerful tool to study gene expression and function in vascular biology, but could also be a promising strategy to treat cerebrovascular disease. For gene transfer to the vascular system, recombinant adenoviruses are the most efficient vectors. Nitric oxide (NO) is a potent vasodilator and an essential regulator of cerebral vascular tone. Impaired production and biological activity of NO contribute to cerebrovascular disorders including cerebral vasospasm after subarachnoid haemorrhage (SAH). Recently, we have studied the transfer and functional expression of recombinant endothelial nitric oxide synthase gene (eNOS) to cerebrovascular bed both in vivo and ex vivo. Our findings concerning cerebral vascular eNOS gene transfer are reviewed in this article, and the potential use of eNOS gene therapy for intracranial disease is also discussed. Although the feasibility of this approach has been demonstrated in animal models, currently available vectors have a number of technical and safety limitations that have to be solved before eNOS gene therapy can be applied in clinical settings.

43

\section{ENDOTHELIN MODULATION OF SKELETAL MUSCLE ARTERIOLAR TONE FROM HYPERTENSIVE RATS}

J.C. Falcone

Department of Physiology \& Biophysics, University of Louisville, U.S.A.

Increased peripheral resistance may be associated with essential hypertension. We have shown that myogenic (pressure-induced) constriction was enhanced in arterioles from hypertensive compared to normotensive animals. Therefore, our objective was to determine if this enhanced myogenic constriction was endothelium dependent. We utilized isolated, cannulated, arterioles (80 to 110 microns) from the rat cremaster muscle of Spontaneously Hypertensive (SH) and Normotensive (WKY) rats. Diameter was measured in response to step changes in intraluminal pressure with and without an intact endothelium. Intrinsic tone developed (approx. 74\% of passive). A comparison of the pressure-diameter relationships of both $\mathrm{SH}$ and WKY demonstrated that the myogenic response from 50 to $150 \mathrm{cmH} 2 \mathrm{O}$ was endothelium-independent. However, endothelium denudation abolished tone at pressures greater than $170 \mathrm{cmH} 2 \mathrm{O}$. In other experiments, the SH endothelium-dependent arteriolar constriction remained intact after inhibiting the formation of prostaglandins with diclofenac (105M; 30 minutes). In contrast, treatment with the endothelin-A (ET-A) receptor antagonist, BQ-123 (10-7M; 30 minutes), abolished the high pressure tone without altering endothelium-independent responses. These data suggest that the endothelium of larger microvessels responds to high pressure by releasing the vasoconstrictor endothelin; perhaps to protect smaller vessels (those with little or no smooth muscle) from damaging pressure while themselves adding to peripheral resistance.

44

NOVEL ASPECTS OF ANGIOTENSIN II SIGNALLING IN VASCULAR SMOOTH MUSCLE

B. Lassegue, M. Ushio-Fukai, K.K. Griendling

Division of Cardiology, Emory University School of Medicine, Atlanta, USA

Many effects of angiotensin II (AngII) in vascular disease are ascribed to its potent stimulation of vascular smooth muscle cells (vsmc). Within seconds of AngII binding to the AT1 receptor, phospholipase C (PLC) beta 1 is activated by heterotrimeric G protein subunits alpha q/11, 12 and beta/gamma. PLC gamma is subsequently activated by a tyrosine kinase. Transient activation of PLCs is followed by sustained hospholipase D activation via G protein subunits alpha 12, beta/gamma, calcium, protein kinase C and src. Concomitantly, stimulation of phospholipase A2 initiates arachidonic acid signalling. Internalization of the AT1 receptor/agonist complex into membrane domains such as caveolae where effectors are localized is required for sustained AngII signalling. AngII also activates members of kinase cascades such as JAK/TYK/STAT, src, ras, and MAPK. Recently, reactive oxygen species have emerged as crucial components of AngIImediated signal transduction in vsmc. Both superoxide and hydrogen peroxide are produced intracellularly via activation of an NADH oxidase, and these molecules serve to mediate downstream signalling events such as activation of p38MAPK and gene transcription. Thus, AngII activates a remarkable spectrum of signalling pathways, and the integration of these diverse signals directs and modulates the physiological and pathophysiological effects of this hormone on vsmc.

INABIS 98

J Vasc Res 1998;35(suppl. 3) 


\section{CALCIUM-DEPENDENT AND INDEPENDENT ACTIVATION OF THE ENDOTHELIAL NO SYNTHASE}

I. Fleming

Institute of Cardiovascular Physiology, University of Frankfurt, Germany

Mechanical forces generated at the endothelium by pulsatile blood flow are important in ensuring the continuous release of nitric oxide (NO) which modulates local vascular tone as well as cell signalling and gene expression. The constitutive endothelial NO synthase (eNOS), can be activated in response to an increase in [Ca2+]i following stimulation with receptor-dependent agonists such as acetylcholine and bradykinin. However, eNOS can also be activated by shear stress and isometric contraction in the absence of a maintained increase in $[\mathrm{Ca} 2+]$ i via a tyrosine kinase-dependent mechanism involving its phosphorylation, redistribution within the cytoskeleton/caveolae and the activation of one or more regulatory eNOS-associated proteins.

\section{6}

THE INVOLVEMENT OF LOCALIZED CA2+ GRADIENTS IN SUBCELLULAR CA2+ DISTRIBUTION, ACTIVITY OF CAPACITATIVE CA2+ ENTRY AND NITRIC OXIDE SYNTHASE IN ENDOTHELIAL CELLS

W.F. Graier, J. Paltauf-Doburzynska, G. Paltauf*, K. Posch, G.M. Kostner

Departments of Medical Biochemistry and *Experimental Physics, University of Graz, Graz, Austria

Recently evidence for an insulated and localized $\mathrm{Ca} 2+$ signalling in the subplasmalemmal space of endothelial cells was provided (Graier et al., J. Physiol. Lond. 506: 109-125, 1998). This study was designed to investigate the contribution of the two major phenomena of the subplasmalemmal $\mathrm{Ca} 2+$ control, ryanodine-sensitive $\mathrm{Ca} 2+$ release $(\mathrm{RsCR})$ and $\mathrm{Na}+\mathrm{Ca} 2+$ exchange $(\mathrm{Na} / \mathrm{CaX})$ in bradykinin $(\mathrm{Bk})$-induced $\mathrm{Ca} 2+$ release, capacitative $\mathrm{Ca} 2+$ entry (CCE) and nitric oxide synthase (eNOS) in freshly isolated bovine coronary artery endothelial cells. 1. Using deconvolution microscopy fura-2 was found throughout the whole cytosol, while FFP-18 was exclusively in the cell membrane. Thus, perinuclear ([Ca2+]peri) and subplasmalemmal $([\mathrm{Ca} 2+]$ sub) $\mathrm{Ca} 2+$ concentration were monitored using fura- 2 and FFP-18. 2. Inhibition of $\mathrm{Na} / \mathrm{CaX}$ by lowering extracellular $\mathrm{Na}+$ concentration augmented the Bk-induced [Ca2+]peri signal in $\mathrm{Ca} 2+-$ free solution. This effect was abolished when RsCR was prevented with $25 \mu$ mol 1-1 ryanodine, while inhibition of RsCR had no effect on Bk-induced increase in $[\mathrm{Ca} 2+]$ peri without inhibition of $\mathrm{Na} / \mathrm{CaX}$. 3. Initiating RsCR by $200 \mathrm{nmol} 1-1$ ryanodine increased [Ca2+]sub, while [Ca2+]peri remained constant. However, when $\mathrm{Na} / \mathrm{CaX}$ was prevented, ryanodine was also able to elevate [Ca2+]peri. 4. Blockage of RsCR diminished $\mathrm{Ca} 2+$ extrusion to stimulation with $\mathrm{Bk}$ in normal $\mathrm{Na}$ + containing solution. 5. Inhibition of RsCR blunted Bk-activated CCE, while inhibition of $\mathrm{Na} / \mathrm{CaX}$ during stimulation enhanced $\mathrm{CCE}$. 6. Although direct activation of RsCR failed to activate eNOS, inhibition of RsCR diminished the effect of ATP and Bk on eNOS, while the effect of thapsigargin remained unchanged. These data suggest that during stimulation subplasmalemmal RsCR occurs, which contributes to the activities of CCE and eNOS. Thus, the function of the subplasmalemmal Ca2+ control unit (SCCU; Graier et al., J. Physiol. Lond. 506: 109-125, 1998.) must be extended as a regulator for CCE and eNOS. 
Object: Oxyhemoglobin $(\mathrm{OxyHb})$ is one of the most important spasmogens for cerebral vasospasm that follows aneurysmal subarachnoid haemorrhage (SAH). The cytotoxicity effect of OxyHb has been documented in endothelial and smooth muscle cells, however, the pattern of cell death, necrosis or apoptosis, as a final stage of cell damage, has not been demonstrated. This study was undertaken to determine if $\mathrm{OxyHb}$ induces apoptotic changes in cultured bovine aortic endothelial cells. Methods: Confluent bovine aortic endothelial cells were treated with $\mathrm{OxyHb}$ in a concentration and time dependent manner. Cell density was assayed by counting the number of cells that attached to the culture dishes after exposed to OxyHb. To identify apoptotic changes, three specific methods: DNA fragmentation (electrophoreses), Apoptotic bod (transmission electron microscopy) and cleavage of poly (ADP-ribose) polymerase (PARP) (Western Blotting) were employed. Conclusions: OxyHb decreased cell density in a concentration and time-dependent manner. DNA analysis showed a pattern of internucleosomal cleavage characteristic of apoptosis (DNA ladder). Transmission electron microscopy demonstrated condensation of nuclei and apoptotic bodies in OxyHb treated endothelial cells. Western blotting using PARP antibody revealed that 116 $\mathrm{kDa}$ PARP was cleaved to $85 \mathrm{kDa}$, an apoptosis-related fragment. These results for the first time demonstrated that OxyHb induced apoptosis in cultured endothelial cell.

48

NITRIC OXIDE SYNTHASE AND GROWTH FACTOR EXPRESSION IN FLOW-INDUCED ARTERIAL REMODELLING IN RAT MESENTERIC VASCULATURE

D.A. Tulis, J.L. Unthank*, R.L. Prewitt

Eastern Virginia Medical School, Norfolk, VA 23501 and

*Indiana University Medical Center, Indianapolis, IN 46202

This study was designed to characterize structural remodelling of male Wistar rat mesenteric arteries exposed to elevated blood flow in vivo for 1, 3, or 7 days. A series of arterial ligations induced blood flow elevations in ileal and second-order branch arteries compared to same animal control vessels while maintaining normal mean arterial pressures. The primary flow-mediated force in both vessels was shear stress with possible involvement of acute stretch-induced wall stress in the ileal artery. Significant lumen expansion and medial wall hypertrophy concomitant with increases in extracellular connective tissue occurred in the high flow arteries in a time-dependent fashion. Wall thickness:lumen diameter ratios did not change in any vessel at any time, suggesting normalization of flow-induced wall stress occurs through vascular remodelling. Immunostaining for proliferating cell nuclear antigen and nuclear profile analyses indicate medial SMC and intimal EC hyperplasia contributed to flow-induced remodelling of the vessel wall. Endothelial NOS immunoreactivity was detected in the high flow vessels at all time points. Results from in situ hybridization revealed significantly elevated PDGF-A mRNA expression in the media after 24 hours and in the endothelium after 3 and 7 days in the high flow vessels. The findings from this study suggest flowstimulated arterial remodelling in vivo involves SMC and EC hyperplasia and increases in extracellular connective tissue. This vessel wall restructuring may involve the actions of NO and PDGF-A as regulators of flow-stimulated growth. 
49

EVIDENCE FOR VIP AND NO AS DUAL NEUROTRANSMITTERS IN CEREBRAL ARTERIES

R.M. Wadsworth, J.D. Matthew, A.J. Gaw, A.R. MacPhaden* University of Strathclyde, Glasgow, Scotland and *Royal Infirmary, Glasgow, Scotland

Nerve fibres in the adventitial layer of sheep middle cerebral artery were found to contain vasoactive intestinal peptide (VIP) and neuronal type NO synthase (NOS) by immunocytochemistry with specific antibodies. Staining of serial sections demonstrated that VIP and NOS are present in the same nerve fibres. Relaxation of rings of sheep middle cerebral artery, elicited by field stimulation of intramural nerves, was inhibited by incubation with VIP antiserum 1:256, or by the inhibitor of neuronal NOS, L-NAPNA 100uM. Relaxation of sheep middle cerebral artery rings by addition of VIP (20-200 nM) phosphodiesterase inhibitor, zaprinast 10 uM. Addition of VIP $200 \mathrm{nM}$ to rings of sheep middle cerebral artery produced a 2.4 fold increase in cyclic-GMP content measured by radioimmunoassay, and this was prevented by preincubation with L-NOArg $100 \mathrm{uM}$. It is concluded that VIP-induced vasodilatation in the cerebral artery occurs via activation of NOS and formation of cyclic-GMP. The results suggest that neurally-mediated vasodilation of the sheep middle cerebral artery requires the participation of both VIP and neuronal NOS.

50

\section{PRESERVATION TECHNIQUES TO ALLOW ACCURATE MEASUREMENT OF BLOOD VESSEL STRUCTURAL CHANGE}

J.G. Dickhout, R.M.K.W. Lee

Department of Anaesthesia, McMaster University, Hamilton, Ontario, Canada.

We have previously observed that blood vessels from 4-week-old spontaneously hypertensive rats (SHR) and normotensive WKY shortened between $30-40 \%$ ( $\mathrm{SHR}=29 \pm 4 \%$,WKY=39 $\pm 3 \%$ ) when excised. This process causes thickening of the vessel wall and affects lumen diameter. We therefore studied different fixation techniques on the structure of maximally-relaxed large mesenteric arteries from 4week-old SHR and WKY. Vessels were fixed either in vitro on micropipettes at their in vivo pressure of $70 \mathrm{mmHg}$, or in situ by perfusion at a flow rate of $1 \mathrm{~mL} / \mathrm{min} / 100 \mathrm{~g}$ of body weight. Vessels were then measured under confocal microscopy. No significant difference in lumen area was found between in vitro and in situ fixed vessels. Medial volume per unit length was also similar between in vitro and in situ fixed arteries, but was significantly greater in SHR than WKY. Thus our in situ fixation method preserved lumen size as compared to vessels fixed at in vivo pressure, and these pressurized vessels had not shortened since they showed similar medial volume per unit length as in in situ fixed arteries. Closer examination of the in situ fixation showed that perfusion pressures were increased with the introduction of the fixative, causing an increase in lumen diameter which eventually attained $85 \%$ in SHR, and $91 \%$ in WKY of their in vivo lumen diameter. We conclude that both fixation methods provide adequate preservation of in vivo artery structure and eliminate distortions introduced by retraction of vessels upon excision. (Supported by the Heart and Stroke Foundation of Ontario) 
51

MIDDLE CEREBRAL ARTERY FUNCTION AFTER ISCHAEMIA, REPERFUSION AND THROMBOLYTIC THERAPY

M.J. Cipolla*, N. Lessov, W.M. Clark

Department of Neurology and *Division of Vascular Surgery, Oregon Health Sciences University

We have previously demonstrated that the myogenic activity of middle cerebral arteries (MCAs) that were ischaemic for 2 hours and reperfused for 2 minutes was similar to that of nonischaemic control arteries (Stroke 1997 28:176-80). In the present study, we investigated the combined effect of ischaemia and tPA exposure on diameter regulation of MCAs. The intraluminal suture model of focal cerebral ischaemia was used to induce 2 hours of ischaemia, after which occluded MCAs were removed and studied in vitro using an arteriograph system that allowed control of transmural pressure and measurement of lumen diameter. Arteries were either nonischaemic (control, $\mathrm{n}=8$ ) or Ischaemic and perfused with 400 micrograms $/ \mathrm{mL}$ tPA (tPA, $\mathrm{n}=6)$. After a 1 hour equilibration at $75 \mathrm{mmHg}$, pressure was increased to $125 \mathrm{mmHg}$ and diameter recorded. Control arteries developed $22+/-3 \%$ tone during equilibration at $75 \mathrm{mmHg}$ and responded myogenically when pressure was increased to $125 \mathrm{mmHg}$, decreasing diameter from $232+/-8$ microns to $229+/-6$ microns (n.s.) and increasing the level of tone to $26+/-2 \%$ (n.s. vs. $75 \mathrm{mmHg}$ ). The tPA arteries developed a similar level of tone as control arteries $(24+/-4 \%$, n.s.). However, increasing pressure to $125 \mathrm{mmHg}$ caused an increase in diameter from $228+/-15$ to $270+/-10$ microns, decreasing the level of tone to $12+/-3 \%$ ( $\mathrm{p}<0.01 \mathrm{vs.} 75 \mathrm{mmHg}$ ). The slope of the pressure vs. diameter curve for control arteries was negative $(-0.06+/--0.01)$, but was positive for the tPA arteries $(0.86+/-0.27)$, demonstrating a loss of diameter regulation and myogenic reactivity in the tPA arteries. These results demonstrate that the combination of ischaemia and tPA perfusion alters cerebrovascular function. The loss of myogenic reactivity in these arteries may have profound effects on cerebrovascular resistance and autoregulation of cerebral blood flow during or after reperfusion.

52 MITOGEN-ACTIVATED PROTEIN KINASE IS INVOLVED IN THE PATHOGENESIS OF CEREBRAL VASOSPASM

A.Y. Zubkov, K. Ogihara, P. Tumu, A.I. Lewis

Department of Neurosurgery, University of Mississippi Medical Center, Jackson, MS, USA

Cerebral vasospasm is a major cause of mortality and morbidity in the patients suffering from subarachnoid haemorrhage (SAH). Pathogenetic mechanism on the cell signal transduction levels were not completely clarified. MAP kinase plays an important role in smooth muscle contraction to arterial haemolysate. Isometric tension studies and western blot were used for this purpose. MAP kinase inhibitor PD98059 was able to significantly inhibit contraction to haemolysate and relax the artery, already contracted with $10 \%$ haemolysate. Western blot studies showed that MAP kinase was activated within 1 minute after stimulation with $10 \%$ haemolysate and maintained activity for at least 120 minutes. The peak of MAP kinase activation was at 10 minutes of incubation with $10 \%$ haemolysate. Conclusion: MAP kinase appears to play an important role in cerebral smooth muscle contraction. It may be a key substrate leading to pathologic changes in the cerebral arteries affected by cerebral vasospasm. 

REDUCED RENAL MASS HYPERTENSION AND ELEVATED DIETARY SALT INTAKE

J. Lombard, J. Frisbee, D. Weber, N. Rusch, Y. Liu

Department of Physiology; Medical College of Wisconsin; Milwaukee, WI; USA

Our laboratory is investigating vasodilator responses in resistance vessels of rats with short term (3 days) and chronic (4-6 weeks) reduced renal mass hypertension (RRM-HT) and vessels of normotensive rats on short term and chronic high salt (HS) diets $(4 \% \mathrm{NaCl})$. In situ cremasteric arterioles of rats with short term and chronic RRM-HT and arterioles of rats on short term and chronic HS diets exhibited impaired relaxation in response to acetylcholine, cholera toxin, and iloprost compared to vessels of normotensive controls on a low salt (LS) diet $(0.4 \% \mathrm{NaCl})$. Isolated skeletal muscle resistance arteries (SRA) of normotensive rats on the HS diets exhibited an impaired relaxation in response to hypoxia, acetylcholine, and iloprost compared to those of LS controls. Pial arterioles of animals on a short term HS diet also exhibited an impaired dilation in response to acetylcholine and iloprost. Vasodilator responses of SRA from animals on a short term HS diet could be restored by continuous infusion of a low dose (5-6 ng/ $/ \mathrm{kg} / \mathrm{min}$, i.v.) of angiotensin II. These results indicate that both hypertension and high salt diet lead to rapid functional alterations in arterioles and resistance arteries, and that impaired vasodilator responses in animals on a HS diet may be mediated by angiotensin II suppression.

54

MODELLING BRAIN ARTERIOVENOUS MALFORMATIONS: A REVIEW

G.J. Hademenos, T.F. Massoud, E. Gao, S. Joshi,

J. Pile-Spellman, W.L. Young

Columbia University College of Physicians and Surgeons, Columbia University, University of Dallas, and UCLA Medical Center

Brain arteriovenous malformation (AVMs) are congenital vascular lesions that can occur anywhere in the central nervous system and consist primarily of three distinct components: (1) arterial feeders, (2) a conglomerate of enlarged abnormal vessels (nidus), and (3) draining veins. The abnormal low-resistance, high-flow shunting of blood within the AVM without an intervening capillary bed causes additional structural fatigue, further enlargement, and possible rupture. Haemorrhage is the most serious sequela of AVMs, accounting for $50 \%$ of their clinical presentation, a $10 \%$ to $17 \%$ death rate, and a > > severe disability rate of $20 \%$ to $29 \%$. The in vivo identification of a cause or mechanism of haemorrhage has remained elusive due to the delicate nature of the AVM nidus vessels and the resultant inaccessibility of catheters intranidally. Given these limitations, the primary mechanism of haemorrhage is believed to be hemodynamic in nature. The flow of blood and the resultant forces exert a large shear stress on the walls of the abnormal nidus vessels causing additional structural fatigue and eventual rupture. Knowledge of the biophysical and hemodynamic interactions and their role in the development and rupture of brain AVMs has significantly advanced current understanding in the management of AVMs and serves as the basis for improved techniques in the diagnosis and therapy of AVMs. One way to advance the understanding of the role of hemodynamics in the mechanisms leading to AVM rupture is the development and implementation of models. The purpose of this paper is to review: (1) the types of models applicable to AVM physiology; (2) advantages, disadvantages, and limitations of each of these models; and (3) future developments of modelling techniques to improve the applicability of models in the identification of underlying mechanisms of AVM rupture. 
Endothelins role in a wide variety of vascular diseases and phenomena are widely documented. Endothelin-1 (ET) role in subarachnoid haemorrhage $(\mathrm{SAH})$ induced vasospasm is integral, and is reviewed in this abstract. Clinical investigations revealed increased ET concentrations in the CSF of patients who had suffered SAH. Experimental research revealed administration of ET intracisternally reproduced vasospasm in dogs. A variety of factors cause secretion of ET by endothelial cells in SAH, thus stimulating various ET receptors which influence vasospasm. Blockade of ET-A and ET-B2 receptors leads to prevention and reversal of SAH induced vasospasm, indicating stimulation of these receptors on the vasculature smooth muscle leads to vasoconstriction and thus vasospasm. The ET-B1 receptor also plays an important role in vasospasm. Stimulation of this receptor causes vasodilation. This vasodilation appears to be mediated, at least in part, via nitric oxide. More importantly, ET-B1 receptor stimulation has been shown to induce further ET release by the endothelium. This positive feedback is an important mechanism for the production and maintenance of vasospasm and appears to be the major influence of ET-B receptors role in the production of vasospasm. In summary, a variety of factors stimulate the endothelium to release ET in SAH. ET stimulates both the ET-A receptor, which causes a potent vasoconstriction, and the ET-B1 receptor. ET-B1 receptor stimulation by ET leads to further ET release, and also has the added, less potent effect of nitric oxide release and a vasodilation. ET-B2 receptor is also stimulated, which leads to a further vasoconstriction.

56 EFFECTS OF MECHANICAL FORCES ON SIGNAL TRANSDUCTION AND GENE EXPRESSION IN ENDOTHELIAL CELLS S. Chien Departments of Bioengineering and Medicine; University California, San Diego, USA

Mechanical stimuli can modulate gene expression in vascular endothelial cells (EC) following the activation of cis-elements by transcription factors induced by signal transduction pathways. Laminar shear stress activates many EC genes, including monocyte chemotactic protein-1 (MCP-1), which has TPA responsive element (TRE) as the cis-element. Studies on phosphorylation of signalling molecules demonstrate that Focal adhesion kinase-Ras-JNK signalling is an important pathway mediating the shear-induced MCP-1 expression. Integrins and cytoskeleton, as well as receptor tyrosine kinases, also participate in the signalling. With the use of a step-flow channel, the flow reattachment area was shown to have an increase in DNA synthesis, an enhanced promoter activity of the cyclindependent kinase cdc2, and EC apoptosis; these can be correlated with the accelerations of EC mitosis and apoptosis at arterial branch points. In contrast, sustained laminar shear stress causes the modulation of expression of genes to arrest EC cell cycle, and this may provide a molecular basis for the protective function of laminar shear stress in the straight part of the arterial tree against atherogenesis. The effects of mechanical stimuli on signal transduction and gene expression play significant roles in the regulation of physiological functions and in pathophysiological changes in disease. 
57

\section{FUNCTIONAL AND STRUCTURAL CONTROL OF VASCULAR DIMENSIONS BY PRESSURE AND FLOW}

E. VanBavel

Dept. Medical Physics, Academic Medical Center, Univ of Amsterdam, The Netherlands

This contribution aims to provide some general considerations when trying to understand the role of acute and structural responses to flow and pressure in the adaptation of vascular networks. First, functional responses affect structural adaptation by sharing of their stimulus. Thus, elevation of the local pressure results in myogenic constriction, which normalizes wall tension to some extent, reducing the stimulus for inward remodelling or hypertrophy. Second, vascular structure influences functional control. Shear stress in the dilated arterial bed depends on the architecture, and in the coronary circulation decreases towards the capillary bed. This could affect the contribution of flow-dependent dilation in large vs. small vessels during autoregulation. Alternatively, the set-point of the shear stress sensor for functional dilation may well be determined by the long-term average of the shear stress, and thus by the structure. Third: flow and pressure responses (either functional or structural) interact. Any response to the local pressure in network affects the local shear stress, and vice versa. The interaction depends critically on the network design. Due to these complex mechanical interactions (in addition to the cellular interactions), the proper understanding of pressure- and flow-dependent blood flow control flow requires an integrative approach including all these aspects.

58

COMPENSATORY AND MAL-ADAPTIVE ARTERIAL REMODELLING IN RODENT MODELS OF ALTERED BLOOD FLOW

J.G.R. De Mey, P. Schiffers, D. Ceiler, G. Fazzi

Department of Pharmacology, Universiteit Maastricht,

The Netherlands

Compensatory arterial structural changes in response to altered hemodynamics restore normal levels of circumferential wall stress (CWS) and wall shear stress (WSS). Failure of this remodelling may perpetuate arterial injury and promote arterial disease. We compared two recently introduced experimental animal models of "flow-induced" arterial remodelling: parallel rat mesenteric arteries and parallel mouse carotid arteries exposed to elevated ( +70 to $100 \%$ ) or reduced (-80 to 100\%) mean arterial blood flow, which are not and are accompanied by neointima formation, respectively (Am. J. Physiol. 273:H1699-H1709, 1997; Arteriosc. Thromb. Vasc. Biol. 17:2238-2244, 1997). Arterial diameter and media structure were evaluated by in vitro pressure-volume curves and morphometry on cross sections of fixed vessels, respectively. Changes with respect to sham-operated controls can be summarized as follows: $(\mathrm{HF}=$ elevated blood flow; lf $=$ reduced blood flow; +++ = increase, --- = decrease) rat mes/HF rat mes/lf mouse car/HF mouse car/lf outer diameter +++ --- no change --lumen diameter +++ --- no change --- media CSA +++ --- no change +++ neointima no no no yes Calculated CWS and WSS were normalized within 4 weeks time in both HF and lf rat mesenteric vessels. Thus, while structural responses to elevated and reduced blood flow are compensatory in nature in the muscular rat mesenteric arteries, they are mal-adaptive in the elastic carotid artery of mice (this study) and rats (earlier work). In view of this it may be worthwhile to address the role in arterial remodelling of factors that are unevenly distributed over the arterial tree, such as pulsatile hemodynamics, the extracellular matrix components collagen and elastin, and the cytoskeletal components vimentin and desmin. To some extent transgenic mouse models may be helpful in this respect. 
Essential hypertension in humans and most animal models of hypertension is characterized by an increased peripheral vascular resistance. The cause of the resistance increase is the subject of intensive ongoing research. A common feature of human essential hypertension and animal models of primary hypertension is an arteriolar and capillary rarefaction. We have previously proposed that rarefaction is the consequence of inhibited vascular growth during early development. The purpose of the present study was to investigate the consequence of various patterns of arteriolar growth on resistance properties of the vascular network. For this purpose we recorded the topological development of a growing arteriolar network in the chick embryo chorio-allantoic membrane (CAM) at day 7, 10 and 14 of gestation, and measured diameter and length of the vessel segments. By applying Poiseuille's law and assuming all precapillary pressures to be equal, resistance (R) to flow was calculated. The number of segments increased from 543 to 1630 and 2757 on days 7,10 and 14 , whereas $R$ decreased from 466 to 458 and 406 pa.mm-3 at the respective days. By applying a mathematical model, we could explain this pattern by assuming that the growth process is dominated in the first stage by segmental growth(SG),i.e. addition of segments in between branch nodes, and with time converged towards terminal growth(TG), i.e. addition to the most distal part. Adding 250 segments to the day 7 arteriolar tree according to TG increased resistance by 53\%, whereas adding according to SG decreased resistance by $7 \%$. Adding 750 segments to the day 10 tree according to TG increased resistance by $23 \%$, whereas adding according to SG decreased resistance by $6 \%$. We conclude that SG decreases and TG increases resistance. The magnitude of the resistance change depends on tree size and the site where the vessels are coupled to the existing tree. Thus, our study shows that the pattern of early arteriolar growth may have important long-term consequences for the resistance properties of an arteriolar network.

\section{0}

\section{P2 RECEPTORS IN CEREBRAL ARTERIES}

J. Zhang*, B. Sima, R.L. MacDonald, B. Weir

Department of Neurosurgery, University of Chicago, Chicago, IL and *University of Mississippi Medical Center, Jackson, MS

Extracellular nucleotides play an important role in the regulation of cerebral vascular tone and may be involved in cerebrovascular disorders such as vasospasm after subarachnoid haemorrhage. The P2 receptor subtypes and their activation-mediated [Ca2+]i elevation and cerebral arterial contraction have been investigated. Extracellular nucleotides produced a concentration dependent biphasic [Ca2+]i response, and the potency of nucleotides to raise [Ca2+]i was ATPgammaS greater than UDP greater than ATP equal to UDP equal to TTP greater than ADP greater AMP equal to a,B-methylene-ATP equal to 2-SATP greater than adenosine, indicating that P2u receptors were expressed in the rat basilar smooth muscle cells. The effect of UTP, a selective agonist for the P2u receptor, to release Ca2+ from internal stores was reduced by pertussis toxin, by the phospholipase C(PLC) inhibitor 2-nitro-4-carboxyphenyl N, N-diphenylcarbamate (NCDC), and by the Ca2+ -pump inhibitor thapsigargin. The Ca2+ entry induced by UTP was partially attenuated by the receptoroperated Ca2+ channel blocker SK\&F 96365, and by the voltage-dependent Ca2+ channel blocker verapamil. P2 receptor antagonists, suramin and, at higher concentrations, PPADS, reduced the effect of UTP. ATP and UPT produced concentration dependent contraction in dog basilar artery and their effect was reduced by suramin. These results demonstrated that nucleotides activate G-protein coupled P2u receptors to mobilize $[\mathrm{Ca} 2+] \mathrm{i}$ and produce contraction in cerebral arteries. 
61

ALTERATIONS IN VASCULAR ENERGY METABOLISM SEEN USING AN IN VITRO MODEL OF SAH INDUCED CEREBRAL VASOSPASM

J.F. Clark, G. Pyne, T.A.D. Cadoux-Hudson

Vascular Smooth Muscle Research Group, MRC Collaborative Centre, UK

Magnesium (Mg++) plays an important role in the energy metabolism of vascular smooth muscle (VSM). It has been shown to stabilize the slowly cycling cross bridge state, which VSM employs to maintain long periods of tension at low energy cost. CSF from patients with vasospasm after SAH has previously been shown to stimulate oxygen consumption \& tension generation in the porcine carotid artery, but the relationship between $\mathrm{Mg}++\&$ vasospasm is yet to be established. The aim of these investigations is to establish a correlation between tension generation and energy metabolism under $\mathrm{Mg}++$ depleted \& $\mathrm{Mg}++$ loaded conditions. Lengths of pig carotid artery were mounted between two clamps as strips or two hooks as rings for isometric force measurements. The pig carotid arteries were incubated in physiological saline solution containing $0 \mathrm{mM} \mathrm{Mg++}, 1.2 \mathrm{mM} \mathrm{Mg++}$ or $12 \mathrm{mM} \mathrm{Mg++} \mathrm{for} \mathrm{two} \mathrm{hours.} \mathrm{It} \mathrm{was} \mathrm{found} \mathrm{that} \mathrm{the} \mathrm{CSFv} \mathrm{caused} \mathrm{the}$ muscle to generate $72+1-8 \%$ of Fmax. Although the $\mathrm{Mg}++$ loaded tissue's response to CSFv with respect to percentage increase from baseline did not differ from control, the basal 02 consumption was lowered from $0.37+/-0.007$ to $0.26+/-0.014 \mathrm{mMols} 02 \mathrm{~min}-1 \mathrm{~g}$ dwt- 1 . Maximal contraction was lowered under $\mathrm{Mg}++$ loaded conditions to $54 \%$ of control. $\mathrm{Mg}++$ depletion alone does not appear to have either deleterious or beneficial effects. These results suggest that Mg++ may have some protective effect against the stimulation by CSFv. This could be effected by the aforementioned stabilization of cross bridges, or other mechanisms.

62

\section{THE ROLE OF NA-H EXCHANGE IN MYOCARDIAL ISCHAEMIC AND REPERFUSION INJURY: THERAPEUTIC} IMPLICATIONS

M. Karmazyn

Department of Pharmacology and Toxicology, University of Western Ontario, Canada

The myocardial $\mathrm{Na}-\mathrm{H}$ exchanger (NHE) represents one of the major mechanisms for intracellular $\mathrm{pH}$ regulation particularly under conditions of excessive proton production as occurs during ischaemia. At least 6 isoforms of the antiporter have thus far been identified although the NHE1 subtype appears to be the primary, if not sole, isoform found in the mammalian myocardium. The extrusion of protons is electroneutral and occurs concomitant with sodium influx. Under Ischaemic conditions the activity of the Na-K ATPase is reduced such that NHE activity during ischaemia can result in excessive intracellular sodium accumulation which then in turn elevates intracellular calcium levels through the Na-Ca exchanger. Numerous studies have demonstrated that pharmacological inhibition of NHE either with amiloride or its analogues or the more newly-developed NHE1 selective inhibitors such as HOE 642 (cariporide) or EMD 85131 results in marked cardioprotective effects. Such protection has been demonstrated with respect to numerous parameters including reduction in infarct size, improved function, attenuation of arrhythmias, energy metabolite preservation, reduction in calcium overload as well as decreased apoptosis. Using an in vivo coronary artery ligation model in the rat, we observed that dietary cariporide significantly attenuates acute postinfarction responses with respect to a variety of parameters. In particular, ventricular fibrillation and mortality are completely abolished by this treatment. In addition to cardioprotective affects against ischaemia, NHE inhibitors also block the ability of various agents such as endothelin-1 or alpha1 adrenergic agonists to augment myocardial injury. Moreover, the direct toxic effects of various factors including lysophosphatidyl choline (LPC) and hydrogen peroxide are attenuated by NHE inhibition. Further evidence that NHE plays an important role in the Ischaemic myocardium stems from the observation that injurious interventions such as ischaemia, LPC or hydrogen peroxide rapidly upregulate NHE1 gene expression in the heart. In contrast, a cardioprotective approach consisting of Ischaemic preconditioning downregulates NHE1 mRNA expression. The potential role of NHE in chronic postinfarction responses has also began to be explored. Early results suggest that inhibition of the antiporter may limit ventricular remodelling suggesting that potential beneficial effects against development of heart failure may be identified with this treatment although substantial future research is still necessary to delineate this. The impressive ability of NHE inhibitors to protect the Ischaemic myocardium as demonstrated in numerous experimental studies has resulted in the development of a large multicentered clinical study to evaluate cariporide in high risk patients with acute coronary syndromes, the so-called GUARDIAN study, the results of which should be available in 1999. Taken together, it is evident that NHE represents a major mechanism for cardiac injury in response to ischaemia and reperfusion. Inhibition of the antiporter, particularly with NHE1-specific inhibitors, represents an effective approach to cardiac protection potentially superior to other cardioprotective strategies. Supported by the Medical Research Council of Canada 
63

\section{BLOOD FLOW-INDUCED VASCULAR REMODELLING AND HYPERTENSION}

R.L. Prewitt

Department of Physiological Sciences, Eastern Virginia Medical School, USA

It has been known for more than a century that the size of the lumen of a vessel depends on the rate of blood flow, but before the advent of molecular and cellular techniques, little was known about the mechanism of this relationship. With the discovery of the role of the endothelium in this process, experiments have been performed to explore the signalling pathway from initial mechanotransduction of shear stress to the final remodelling of the media around the larger lumen. In response to increases in shear stress, endothelial cells release nitric oxide and prostacyclin to promote vasodilatation and inhibit platelet aggregation. The resultant increase in circumferential wall stress may play a key role in transmission of the growth signal from the endothelium to the medial smooth muscle cells. In hypertension the arterioles undergo inward, eutrophic remodelling whereby they have the same medial mass rearranged around a smaller lumen. At the initiation of hypertension, the arterioles are severely constricted. Wall shear stress increases in the constricted arterioles, but endothelial dysfunction reduces the release of nitric oxide and uncouples the shear stress signalling pathway for lumenal expansion. As a result, the chronically smaller lumen becomes a structural adaptation to the elevated blood pressure and arteriolar tone returns toward control levels.

64 SUPPRESSED SHEAR-MEDIATED ARTERIAL REMODELLING HYPERTENSIVE AND MATURE RATS

J.L. Tuttle, J.L. Unthank

Department of Surgery, Indiana University, USA

Shear-mediated vascular remodelling has been demonstrated to be of primary importance in collateral development. An intact endothelium has been shown to be essential in this phenomenon. Consequently, shear-mediated collateral development could be altered in animals with endothelial dysfunction. We utilized spontaneously hypertensive and mature rats to determine if vascular remodelling was altered in small resistance arteries, which formed collateral pathways, and were exposed to chronic elevation of shear. In youngnormotensive rats, luminal expansion, intimal hyperplasia and medial hypertrophy were observed one week following abrupt elevation of shear stress. However, in mature animals intimal hyperplasia and medial hypertrophy occurred without luminal expansion. In hypertensive animals, intimal hyperplasia was observed in the collaterals without medial hypertrophy or luminal expansion. The results indicate that shear-mediated regulation of structural arterial diameter is suppressed and the associated wall remodelling altered in two different animal models characterized with endothelial dysfunction. Supported by NIH HL 42898.

\section{5}

\section{SHEAR-MEDIATED LUMINAL EXPANSION AND WALL REMODELLING IN COLLATERAL RESISTANCE ARTERIES}

J.L. Unthank

Department of Surgery, Indiana University, USA

Studies were performed to evaluate the role of wall shear in the luminal expansion of small resistance arteries which form collateral pathways after abrupt arterial occlusion. In 200g Wistar rats, 3-4 sequential ileal arteries were ligated. Subsequently, blood flow and wall shear rate (WSR) in collateral arteries increased 275 and 175\%, respectively. This increase in blood flow sustained normal tissue perfusion. Maximum inner arterial diameter at the beginning of the collateral path was increased $\sim 30$ and $65 \%$ at 1 and 4 weeks. Regions of the collateral path experiencing smaller increases in flow and shear had smaller increases in diameter. Increases occurred in all wall areas while the ratio of medial thickness to luminal radius was preserved. Comparisons of nuclear numbers and density between collateral and control arteries indicated that proliferation occurred first in the intima and then the media. This proliferation was followed by cellular regression after wall shear rate had been normalized. These results support the hypotheses that luminal expansion in collaterals is correlated with WSR, and that the relationship between medial thickness and luminal diameter is maintained. However, cell density is altered during luminal expansion associated with abrupt elevation of WSR. Supported by NIH HL42898. 
66

RENAL MICROVASCULAR REACTIVITY TO ANGIOTENSIN II IS ENHANCED IN ANGIOTENSIN II-INDUCED HYPERTENSION

J.D. Imig

Department of Physiology, Tulane University School of Medicine, New Orleans, LA, USA

The current studies were performed to determine renal microvascular tone and reactivity in angiotensin II-infused hypertensive rats. Male-Sprague Dawley rats received angiotensin II (60 ng/min) or vehicle via an osmotic minipump. Angiotensin II-infused hypertensive and normotensive shams were studied 5-7 and 11-13 days following implantation of the minipump. Systolic blood pressure (SBP) averaged $117+4 \mathrm{mmHg}(\mathrm{n}=31)$ prior to pump implantation. Angiotensin II infusion increased SBP to $155+7(\mathrm{n}=6)$ and $184+6 \mathrm{mmHg}$ $(n=9)$ on infusion day 6 and 12, respectively. Renal microvascular responses to angiotensin II, norepinephrine or increasing perfusion pressure were observed utilizing the in vitro juxtamedullary nephron preparation. At a renal perfusion pressure of $80 \mathrm{mmHg}$ interlobular and afferent arteriolar diameters of normotensive animals averaged $28+1$ micron and $18+1$ micron, respectively. Diameters of the interlobular arteriole at renal artery perfusion pressures between 80 and $160 \mathrm{mmHg}$ were $12-20 \%$ smaller in $11-13$ day hypertensive rats compared to normotensive controls. Additionally, 5-7 and 11-13 day hypertensive animals had an enhanced responsiveness of the renal microvasculature to angiotensin II. Angiotensin II (10 nM) decreased afferent arteriolar diameter by $27+3 \%$ in the $5-7$ day hypertensive group, by $19+3 \%$ in 11-13 day hypertensive group and by $13+3 \%$ in normotensive animals. In contrast, the afferent arteriolar response to norepinphrine was not enhanced after 5-7 days on angiotensin II administration. These data demonstrate an enhanced renal microvascular tone and enhanced vascular reactivity that is selective for angiotensin II in animals that develop hypertension following infusion of angiotensin II.

\section{7}

INHIBITION OF LOW DENSITY LIPOPROTEIN OXIDATION BY GINKGO BILOBA EXTRACT (EGB)

M. Huang, J-P Li, H. Teoh, R.Y.K Man

Sun Yat-sen University of Medical Science, PR China, Norman Bethune University, PR China, and The University of Hong Kong, Hong Kong, SAR China

The oxidation of low density lipoprotein (LDL) is believed to be an important event in atherogenesis. Oxidized LDL, which is able to elicit some of the biological responses leading to the initiation and progression of the atherosclerotic plaque, is more atherogenic than native LDL. Ginkgo biloba is a traditional Chinese medicine that is used for treating peripheral vascular diseases and cerebrovascular insufficiency. In vitro studies have shown that EGb, an extract from Ginkgo biloba leaves, scavenges various reactive oxygen species as well as peroxyl radicals. The present study was designed to investigate the protective effect of EGb on LDL oxidation. LDL samples were obtained from the plasma of healthy male donors by sequential ultracentrifugation. Native LDL was diluted to $50 \mu \mathrm{g}$ protein per ml with phosphate buffered saline and then pretreated with various concentrations of EGb and/or vitamin $\mathrm{C}$ for 30 minutes. Oxidation of LDL was initiated with $2 \mu \mathrm{M} \mathrm{CuSO} 4$ at $37 \mathrm{oC}$ for $180 \mathrm{~min}$. Conjugated diene formation was measured by continuously monitoring the absorbance of LDL every 4 minutes in a Beckman spectrophotometer. In the range of $0.1-10 \mu \mathrm{g} / \mathrm{ml}$, EGb concentration-dependently inhibited conjugated diene formation during LDL oxidation. Interestingly, a low concentration of EGb, $0.1 \mu \mathrm{g} / \mathrm{ml}$, significantly enhanced the antioxidant effect of vitamin C on LDL oxidation. In addition, EGb concentration-dependently reduced lipid peroxide levels as measured by the amount of thiobarbituric acid-reactive substances (TBARS) formed and retarded the changes in relative electrophoretic mobilities (REM) of OxLDL samples. In conclusion, EGb can protect LDL from oxidation in vitro. The antioxidant actions of EGb, as well as its enhancement of other endogenous antioxidant effects, provide further support for the potential anti-atherogenic role of EGb. 
Ischaemia is accompanied by mitochondrial dysfunction leading to fall in ATP concentration and phosphorylation potential, and loss of cellular ion homeostasis. Particularly, the raise in intracellular calcium concentration due to bioenergetic failure is believed to be harmful for cells. Following brief Ischaemic insults, mitochondrial function is usually normalized in the early reperfusion period and the ion concentration gradients are re-instituted. However reperfusion, especially following long-lasting Ischaemic periods, may be accompanied by secondary mitochondrial failure, which can trigger a lethal cascade of events known as apoptosis, or cause necrotic cell death. Recently there is accumulating evidence revealing the possible scenario of pathophysiological and biochemical mechanisms which orchestrate the events playing a significant role in Ischaemic cell death.

69

\section{MECHANISMS OF OXYGEN FREE RADICAL FORMATION IN EXPERIMENTAL FORMS OF HYPERTENSION}

A. Swei, H. Suzuki, D.A. Parks*, F.A. Delano, G.W. Schmid-Schönbein

University of California San Diego, CA and *Univ. Alabama at Birmingham, Birmingham AL

Introduction: The link between the elevation of the arterial blood pressure and the production of vascular lesions remains one of the most elusive issues in arterial hypertension research. Recent evidence in the spontaneously hypertensive rat and the salt dependent Dahl hypertensive strains indicate that there is an excessive production of superoxide anion in microvascular endothelium and in circulating leukocytes. The current studies were designed to examine the role of the endothelial xanthine oxidase as a source for the oxidative stress in the SHR and Dahl forms of hypertension and their normotensive controls. Materials \& Methods: The oxidative stress in mesentery microcirculation SHR and Dahl (salt sensitive/resistant with and without $6 \% \mathrm{NaCl}$ supplementation) were examined with hydroethidine and tetranitroblue tetrazolium, respectively, which form visible products upon reaction with superoxide anion. The xanthine oxidase and xanthine dehydrogenase (XD and XO) activity was measured and blocked by tungsten supplementation as well as by blockade with BOF 4272 (in the case of the SHR). Results: Both models of hypertension exhibit significantly elevated levels of XD and XO and enhanced oxidative stress in both the arterial and venular segments of the microcirculation compared with their respective normotensive controls. The elevation of the oxidative stress and blood pressures can be reduced significantly by blockade of XD and XO. Conclusions: The elevated levels of oxidative stress in the hypertensives may serve a dual role, to enhance on one hand the arteriolar tone and thus elevated central blood pressure and on the other hand to mediate the formation of proinflammatory response with lesion formation. Supported by NIH Grants HL 10881, HL 48676, and DK 43785. 

MESENTERIC ARTERIES

D. Ceiler, J.G.R. De Mey

Dept. of Pharmacology, Universiteit Maastricht, the Netherlands

Increases in arterial blood flow lead to vasodilatation in muscular arteries and resistance arteries/arterioles, including arcading arterioles that are candidate collateral channels in ischaemia. Nitric oxide (NO) is involved in the acute flow-induced vasodilator response. We addressed the chronic role of NO in flow-induced responses. In 8 week old male Wistar Kyoto rats, changes in blood flow (BF) were induced in small mesenteric muscular arteries by ligating every other first order mesenteric side branch in part of the mesenteric vascular bed, hereby reducing BF in ligated vessels (LO) and increasing BF in the intermediate parallel vessels (HI). Four LO and 3 HI were created near either the stomach or the coecum. This model is an adaptation of our earlier ligation model (Am.J.Physiol. 273: H1699H1709) since vessels from the distant unoperated part of the vascular bed could be used as internal controls (CON). BF was measured with a Transonic flow probe in HI, LO and CON within 30 min. after ligation ( $t 0 ; n=9)$. After surgery, rats received either no treatment (NT; $\mathrm{n}=10)$ or chronic administration of L-NAME $(25 \mathrm{mg} / \mathrm{kg} /$ day s.c.; $\mathrm{n}=8)$ Two weeks later BF was measured again. BF was also measured in mesenteric arteries of unoperated 10 week old male rats (sham; $n=6)$ ). No differences in flow were observed between $\mathrm{CON}(0.21 \pm 0.02$ $\mathrm{ml} / \mathrm{min})$ or sham $(0.26 \pm 0.04)$. Ligation of NT arteries reduced flow at $\mathrm{t} 0(0.03 \pm 0.02)$ in LO, which remained low at $\mathrm{t} 2(0.04 \pm 0.01)$. HI arteries of NT rats had a slightly increased flow at t0 (0.45 \pm 0.05$)$, which became significant at 2 (0.54 \pm 0.07$)$. Chronic L-NAME treatment did not significantly alter BF in CON $(0.17 \pm 0.03)$ or LO $(0.03 \pm 0.01)$, but prevented the increase of BF in $\mathrm{HI}(0.27 \pm 0.05)$. Thus, although NO synthase inhibition did not compromise perfusion of the intact mesenteric circulation, it persistently prevented the fall in resistance offered by arcading collateral arterioles. We speculate that the "endothelium dysfunction" observed in hypertension, diabetes, and hyperlipidemia may impede the formation of adequate collateral circulations

71

\section{THE STRUCTURE OF SMALL ARTERIES IN ESSENTIAL HYPERTENSION}

A.M. Heagerty

Department of Medicine, Manchester Royal Infirmary, UK

Essential hypertension is haemodynamically characterised by increases in peripheral vascular resistance and normal cardiac output. Blood flow is modified by small blood vessels and in order to investigate morphological alterations in hypertension, techniques have been established which allow structure to be mathematically predicted or precisely measured. Such methods deliver remarkable concordance with a reduction in lumen diameter of $7-8 \%$ and an increase in media thickness:lumen diameter ratio is associated with the level of pressure, and morphology correlates with left ventricular mass. Pressure is the major determinant of structure. The change itself is due to a re-arrangement of tissue around a narrower lumen, with an increase in medial layers (eutrophic inward remodelling). Also there is a small contribution from hypertrophy. Such changes are found in vascular beds including subcutaneous fat, intestinal and intramyocardial arteries. In the heart this fixed structural change may be pathologically important by reducing vascular reserve. In the Ren II transgenic rat, remodelling is associated with over expression of an integrin. Trials have suggested ACE inhibitors may be superior in reversing remodelling which may be clinically important: if vascular reserve were improved in the coronary circulation, the cardiovascular event rate in treated hypertension might be reduced further. 
K.M. Hannan, R.J. Dilley*, P.J. Little

Cell Biology of Diabetes and *Morphology Laboratory,

Baker Medical Research Institute

All forms of diabetes occur with vascular disease as a major component of the chronic phase or "complications". Recent developments in the understanding of vascular pathology indicate the involvement of a complex interplay between the vascular cells and cells derived from the blood and perivascular compartments. In the vessel wall both endothelial and vascular smooth muscle cells are involved in physiological and pathophysiological vascular perturbations. Relevant cellular functions in the remodelling and atherosclerotic processes include proliferation, apoptosis and migration. Secretory functions including the regulation of extracellular matrix and vasoactive substances are also important. These cellular functions are potentially regulated by the metabolic milieu of diabetes, particularly the hyperglycemia. Our focus is on the sodium hydrogen exchanger (NHE) which has been implicated in a number of the above cellular functions and responses. NHE may play a role either directly or as a consequence of involvement in regulation of the ionic environment, particularly, the control of intracellular $\mathrm{pH}$. In cell culture systems elevated glucose activates NHE and proliferation of vascular smooth muscle but limited data confirmed by our recent results indicate that it inhibits both of these properties in endothelial cells. This article is concerned with the mechanisms by which the biochemical abnormalities of diabetes exert their pathological effects on vascular cells in particular via altering sodium hydrogen exchange activity.

73

REGULATION OF ENDOTHELIAL NITRIC OXIDE SYNTHASE PRODUCTION BY INHIBITION OF HMG-COA REDUCTASE

U. Laufs, M. Endres*, M.A. Moskowitz*, J.K. Liao

Brigham and Women's Hospital, Boston, USA and *Massachusetts General Hospital, Boston, USA

Endothelial-derived nitric oxide (NO) is an important mediator of vascular function. Clinical studies indicate that HMG-CoA reductase inhibitors (statins) improve endothelial function. Treatment of human endothelial cells with statins increased the expression of endothelial NO synthase (eNOS) protein and mRNA expression. Statins increased eNOS mRNA half-life but did not change eNOS gene transcription. Inhibition of mevalonate synthesis by statins not only blocks the formation of cholesterol but also of isoprenoids. The upregulation of eNOS expression by statins was mediated via the inhibition of geranylgeraniol, but not farnesiol. Immunoblot analyses, [35S]GTPgammaS-binding assays and transfection studies revealed that statins upregulate eNOS expression by blocking the geranylgeranylation of the GTPase Rho which is necessary for its membrane-associated activity. Studies with mice showed, that statin treatment upregulates eNOS expression and function independent of serum cholesterol levels. Prophylactic treatment with statins augmented cerebral blood flow and reduced cerebral infarcts in normocholesterolemic mice. These effects of statins were completely absent in eNOS-deficient mice indicating that enhanced eNOS activity by statins is the predominant mechanism by which these agents protect against cerebral injury. Our results suggest that statins provide a novel prophylactic treatment strategy for increasing blood flow and reducing brain injury during cerebral ischaemia. 
MICROVASCULAR ADAPTATIONS TO REDUCED BLOOD FLOW: INTRODUCTION OF A NEW MODEL

D.H. Wang, R.L. Prewitt*

University of Texas Medical Branch, TX, USA and

*Eastern Virginia Medical School, VA, USA

The purpose of this study was to evaluate microvascular development during normal skeletal muscle maturation, and determine the alterations associated with decreased blood flow caused by a decrease in demand. Unilateral orchidectomy was performed on 4-week-old rats to reduce muscle tension and growth of one cremaster muscle. Three weeks later, total blood flow was reduced to $58+9 \%$ measured by the dual-slit velocity technique and $55+9 \%$ by radioactive microspheres and the muscle was smaller compared to the intact contralateral muscle. Blood flow per gram of tissue was not significantly different. Measured by closed-circuit television microscopy, the internal diameters and wall cross-sectional areas of all orders of arterioles $(1 \mathrm{~A}-4 \mathrm{~A})$, and the number of 4As per $3 \mathrm{~A}$ had increased with age in the control muscle. The arcading arterioles increased in length by $35 \%$ as the intact muscle grew, but the number of 3As remained unchanged. Arteriolar length increased but not in proportion to muscle mass. As a result, large and small arteriolar density decreased with age. Thus, during normal skeletal muscle maturation, preexisting arterioles became elongated and only precapillary arterioles increased in number, resulting in a decreased ratio of arteriolar number to tissue mass. Unilateral orchidectomy inhibited the growth of arterioles in both size and number. A reduced diameter of the $1 \mathrm{~A}$ in the orchidectomy muscle resulted in unchanged wall shear rate. Flow-induced shear stress and/or local changes in growth factors are suggested as possible mechanisms mediating the alterations. 
Author Index (numbers refer to abstract number)

Agabiti RE, 37

Alarcon Martinez T, 6

Alyavi AL, 9

Aoki K, 12

Arribas SM, 26

Ballerini L, 4

Balzer M, 40

Benessiano J, 24

Bernanke DH, 47

Bettoni G, 37

Bíbová J, 10

Boegehold MA, 11

Boggis C, 8

Cadoux-Hudson TAD, 61

Castellano M, 37

Castellanos Bisset I, 6

Ceiler D, 58, 70

Cellini M, 7

Chatel D, 24

Chen AFY, 42

Chien S, 56

Christine MM, 5

Cipolla MJ, 51

Clark JF, 61

Clark WM, 51

Coats P, 22

Cole DEC, 8

Cotecchia S, 20

Curras-Collazo MC, 18

Daly CJ, 20

De Mey JGR, 58, 70

DeBlois D, 19

Delano FA, 69

Dickhout JG, 50

Dilley RJ, 72

Dominiczak AF, 26

Dong H, 28, 29

Droogmans G, 33

Eber B, 13

Eggermont J, 33

Elmoselhi AB, 2

Emi K, 25

Endres M, 73
Falcone JC, 43

Fazzi G, 58

Feldman RD, 17

Fleming I, 45

Frisbee J, 53

Gao E, 54

Gaw AJ, 49

Gloe T, 1

Godfraind T, 15

Goloskokova VY, 9

Gonzalez MC, 26

Graier WF, 46

Griendling KK, 44

Groschner K, 40

Grover AK, 2, 5

Guan YY, 41

Hacking W, 59

Hademenos GJ, 54

Hamet P, 19

Hamm HE, 27

Hampl V, 10

Hannan KM, 72

Hayes MJ, 21

Heagerty AM, 71

Henrion D, 24

Herget J, 10

Hillier C, 22

Huang M, 67

Huang Y-T, 30

Hussein MO, 18

Imig JD, 66

Ito Y, 25

Iwabuchi S, 12

Johns L, 41

Joshi S, 54

Kamouchi M, 33

Karmazyn M, 62

Katusic ZS, 42

Kelkar BMS, 3

Kettlun CS, 34

Khan I, 5

Kimura H, 12,

Klein W, 13
Kostner GM, 46

Kowalczuk A, 41

Kristian T, 68

Kwan CY, 35

Kyselovic J, 15

Langman LJ, 8

Lassegue B, 44

Laufs U, 73

Laverty R, 36

le Noble F, 59

Ledingham J, 36

Lee RMKW, 50

Lehoux S, 16

Lelkes PI, 34

Lercher P, 13

Lessov N, 51

Lévy BI, 24

Lewis AI, 47, 52

Li J-P, 67

Liao JK, 73

Liebmann PM, 13

Lintschinger B, 40

Little PJ, 72

Liu Y, 53

Lombard J, 53

MacDonald RL, 60

MacPhaden AR, 49

Malik AB, 27

Man RYK, 67

Marton LS, 41, 12

Massoud TF, 54

Matthew JD, 49

McGrath JC, 20, 26

Mills NL, 23

Minshall RD, 27

Morel N, 15

Moretti M, 7

Moskowitz MA, 73

Mulvany MJ, 37

Murphy TJ, 38

Nikitin NP, 9

Niles WD, 27

Nilius B, 33

\section{INABIS 98}


Nishi A, 25

Nurkiewicz TR, 11

Ogihara K, 47, 52

Padfield PL, 23

Paltauf G, 46

Paltauf-Doburzynska J, 46

Parent AD, 47

Parks DA, 69

Pasini G, 37

Philip I, 24

Piccoli A, 37

Pile-Spellman J, 54

Plantefève G, 24

Pohl U, 1

Porteri E, 37

Posch K, 46

Prewitt RL, 48, 63, 74

Pyne G, 61

Rapoport RM, 55

Rizzoni D, 37

Rodriguez Morales R, 6

Rossi A, 7

Rubanyi GM, 34

Rubin LA, 8

Rusch N, 53

Sakotnik A, 13

Samejima H, 12

Samson SE, 2

Sanchez Cuello L, 6

Schauenstein K, 13

Schiffers P, 58

Schiffrin EL, 39

Schmid-Schönbein GW, 69

Sherman JD, 55

Siesjo BK, 68

Sima B, 60

Slaaf D,59

Smith PR, 21

Spratt J, 23

Stoodley MS, 41

Stoschitzky K, 13

Struijker-Boudier H, 59

Sukovich DA, 34

Suzuki H, 69

Swei A, 69

Tan BKH, 14

Tan CM, 17

Tea B-S, 19

Tedgui A, 16
Teoh H, 67

Tiruppathi C, 27

Torreggiani A, 7

Triggle CR, 28

Tulis DA, 48

Tumu P, 52

Tuttle JL, 64

Uji Y, 25

Unthank JL, 48, 64, 65

Ushio-Fukai M, 44

VanBavel E, 57

Versura P, 7

Vicky S, 5

Vogel SM, 27

Wadsworth RM, 49

Wang DH, 74

Wang R, 31, 32

Waters CR, 34

Webb DJ, 23

Weber D, 53

Weir B, 41, 60

Wibo M, 15

Wigboldus J, 34

Wong BY-L, 8

Wong Navarro R, 6

Wu L, 32

Young WL, 54

Zhang CY, 14

Zhang J, 41, 47, 60, 12

Zubkov AY, 47, 52

Zuccarello M, 55 